\title{
Designing and enhancing the antifungal activity of corneal specific cell penetrating peptide using gelatin hydrogel delivery system
}

This article was published in the following Dove Press journal: International Journal of Nanomedicine

\author{
Chatterjee Amit ${ }^{1,2}$ \\ Shalini Muralikumar ${ }^{3}$ \\ Sargunam Janaki ${ }^{4}$ \\ Meena Lakshmipathy ${ }^{5}$ \\ Kulandai Lily Therese ${ }^{4}$ \\ Vetrivel Umashankar ${ }^{3}$ \\ Prema Padmanabhan ${ }^{5}$ \\ Janakiraman Narayanan' \\ 'Department of Nanobiotechnology, \\ Vision Research Foundation, Sankara \\ Nethralaya campus, Chennai, Tamil \\ $\mathrm{Nadu}$, India; ${ }^{2} \mathrm{School}$ of Chemical and \\ Biotechnology, SASTRA University, \\ Tanjore, Tamil Nadu, India; ${ }^{3}$ Centre \\ for Bioinformatics, Vision Research \\ Foundation, Sankara Nethralaya \\ campus, Chennai, Tamil Nadu, India; \\ ${ }^{4}$ L\&T Microbiology Research Centre, \\ Vision Research Foundation, Sankara \\ Nethralaya campus, Chennai, Tamil \\ Nadu, India; ${ }^{5}$ Department of Cornea, \\ Medical Research Foundation, Sankara \\ Nethralaya campus, Chennai, Tamil \\ Nadu, India
}

Correspondence: Janakiraman Narayanan Department of Nanobiotechnology, KNBIRVO Block Vision Research Foundation, Sankara Nethralaya campus, 4I/I8, College Road Nungambakkam, Chennai 600006, Tamil Nadu, India $\mathrm{Tel}+9 \mid 442827$ I 616 ext 1358 $\mathrm{Fax}+9 \mid 4428254180$ Email drjrn15@gmail.com
Background: Fungal keratitis is a major cause of corneal blindness accounting for more than one-third of microbiologically proven cases. The management of fungal keratitis is through topical or systemic antifungal medications alone or in combination with surgical treatment. Topical medications such as natamycin and voriconazole pose major challenges due to poor penetration across the corneal epithelium. To address the issue various carrier molecules like nanoparticles, lipid vesicles, and cell penetrating peptides were explored. But the major drawback such as non-specificity and lack of bioavailability remains.

Purpose: In this study, we have attempted to design corneal specific cell penetrating peptide using subtractive proteomic approach from the published literature and tried to improve its bioavailability through gelatin hydrogel delivery system.

Material and Methods: Using subtractive proteomic approach two peptides VRF005 and VRF007 were identified on the basis of solubility, cell permeability and amphipathicity. The peptides were modeled for three-dimensional structure and simulated for membrane penetration. The peptides were characterized using circular dichroism spectroscopy, dynamic light scattering and native polyacrylamide gel electrophoresis. Further uptake studies were performed on primary corneal epithelial cells and the stability was analyzed in corneal epithelial tissue lysates. Insilico prediction of peptides showed it to have antifungal activity which was further validated using colony forming assay and time killing kinetics. The duration of antifungal activity of peptide was improved using gelatin hydrogel through sustained delivery.

Results: VRF005 and VRF007 showed $\alpha$-helical structure and was within the allowed region of Ramachandran plot. The simulation study showed their membrane penetration. The peptide uptake was found to be specific to corneal epithelial cells and also showed intracellular localization in Candida albicans and Fusarium solani. Peptides were found to be stable up to 2 hours when incubated with corneal epithelial tissue lysate. Dynamic light scattering, and native polyacrylamide gel electrophoresis revealed aggregation of peptides. VRF007 showed antifungal activity up to 24 hour whereas VRF005 showed activity up to 4 hours. Hence gelatin hydrogel-based delivery system was used to improve the activity. Actin staining of corneal epithelial cells showed that the cells were attached on gelatin hydrogel. Conclusion: We have designed corneal specific cell penetrating peptides using subtractive proteomic approach. Bioavailability and delivery of peptide was enhanced using gelatin hydrogel system.

Keywords: cell-penetrating peptide, gelatin hydrogel, CD spectroscopy, subtractive proteomic approach

\section{Introduction}

The corneal epithelium is the outer most layer of the eye and forms an effective barrier against the entry of most pathogens. The tight junctions (TJs) of the corneal 
epithelium regulate the movement of fluid and macromolecules. ${ }^{1}$ Microbial invasion typically occurs secondary to ocular trauma resulting in penetration of causal organism in the tissue. The deeper penetration through the stroma and Descemet's membrane makes the infection more recalcitrant to treatment. Although there are considerable geographic and seasonal variations in the epidemiology of infectious keratitis, fungal infections are a major cause of corneal morbidity in tropical and agricultural countries. Filamentous fungi (Fusarium and Aspergillus) and yeast-like fungi (Candida) are the most frequently isolated organisms in fungal keratitis. ${ }^{2}$ Currently, three classes of antifungal drugs such as polyenes (eg, natamycin and amphotericin), azoles (derivatives of imidazoles), and pyrimidines (5-fluorocytosine) constitute the medical armamentarium in the management of fungal keratitis. ${ }^{3}$ Almost all antifungal drugs show poor corneal epithelial penetration resulting in suboptimal bioavailability, making fungal keratitis a potentially devastating condition. This, then, warrants the search for an antifungal agent with good cell penetration and sustained bioavailability.

Although nanoparticles, lipid vesicles, cell-penetrating peptides (CPPs), and CPP-conjugated therapies (CTTs) are now being used for topical drug delivery with high clinical efficacy, they lack cell specificity and bioavailability. ${ }^{4}$ To address the issue of cell specificity, Heffernan et $\mathrm{al}^{5}$ reported a method to generate glial-specific CPP for multiple sclerosis, from the surface proteins of lymphocytic choriomeningitis virus (LCMV) which infects glial cells. Bioavailability was enhanced by targeting conserved amino acid residues between antimicrobial peptide and CPP ${ }^{6}$ but none of them were able to generate tissuespecific peptides.

Semba et $\mathrm{al}^{7}$ published a series of articles on human eye proteome ${ }^{8-10}$ listing out the set of abundant proteins in different parts of the eye (choroid, retina, lens, iris, ciliary body, etc). Dyrlund et $\mathrm{al}^{11}$ identified and quantified the list of proteins in the layer of the cornea. Hence, in the present study, we attempted to develop corneal-specific CPP by applying subtractive proteomic approach followed by in silico study on the list of proteins published by Semba et al and Dyrlund et al. We successfully identified two CPPs which were validated further experimentally for its structure, cellular uptake, and antifungal activity. Of the two CPPs, one showed antifungal activity for only 4 hours. Hence, we used gelatin hydrogel as a delivery system to improve the duration of its antifungal activity up to 24 hours.

\section{Materials and methods Ethical approval}

The study was reviewed and approved by the local ethics committee at Vision Research Foundation, Sankara Nethralaya, Chennai, India, and the committee deemed that it conformed to the principles of research in accordance with the Declaration of Helsinki (ethics no. 489-2015-P). The study was conducted on the enrolled patients who underwent refractive error correction surgery by obtaining duly signed informed consent forms from the patient/guardian as a part of clinical management.

\section{Peptide designing strategy}

Corneal-specific CPPs were designed by creating seven datasets and by consolidating the proteome from the published literature. Dataset 1 consists of common corneal proteins across three regions of cornea (epithelium, endothelium, and stroma). ${ }^{11-13}$ Similarly, dataset 2 consists of 8,258 proteins expressed in the lens, cornea, choroid, aqueous, retina, tears, and vitreous regions. They were subjected to blast analysis to find conserved retinal-specific proteins. ${ }^{8-10,14}$ Further, ID match analysis was performed between dataset 1 (609 proteins) and dataset 2 (672 proteins) to identify dataset 3 (338 proteins) consisting of conserved corneal specific proteins. Further, the corresponding sequences were batch retrieved from Uniprot database.

A total of 1,845 CPPs were downloaded from CPP database (http://crdd.osdd.net/raghava/cppsite) and were subjected to redundancy check. These peptides were further analyzed to filter out the ambiguous peptides with undesirable chemical modifications. These 731 nonredundant CPPs made our dataset 4. As a next step, dataset 4 (731 nonredundant $\mathrm{CPPs}$ ) was subjected to blast analysis with dataset 3 (338 corneal-specific protein sequences) using CLC Genomics Workbench 0.1, set to default parameters, toward identifying the commonly conserved sequences among corneal-specific proteins and CPP dataset. This analysis led us to $218 \mathrm{CPPs}$ which were further filtered with the criteria of $>60 \%$ sequence identity match and CPP of length 6-16 residues. The peptides surpassing the filtering criteria were further subjected to amphipathicity prediction using the online server AMPHIPASEEK (https:// npsa-prabi.ibcp.fr/cgibin/npsa automat.pl?page=/NPSA/ npsa amphipaseek.html) and also to predict its secondary structure. AMPHIPASEEK provides a score for every residue between a range of 0 and 5 for the given peptide sequences. Higher scores imply high amphipathic nature and vice versa $(0=$ low and $5=$ high $)$. Hydropathy values were 
calculated using the online server (https://www.peptide2. com/N peptide hydrophobicity hydrophilicity.php). Following the previously mentioned filtration criteria, dataset 5 consisting of 62 CPPs was obtained.

We downloaded the entire protein dataset of Fusarium solani from the FTP site of NCBI database to design CPP which can penetrate both corneal epithelium and $F$. solani. This served as our dataset 6 . Further comparisons of dataset 4 (731 nonredundant $C P P s)$ vs dataset 6 ( $F$. solani) proteome resulted in the list of $140 \mathrm{CPPs}$ with the abovementioned selection criteria. These 140 CPPs constitute our dataset 7. Finally, to arrive at a CPP which will have the potential to penetrate both corneal epithelium and $F$. solani, a comparison between dataset 5 vs dataset 7 was done which resulted in 38 CPPs. The $38 \mathrm{CPPs}$ were passed through the criteria of peptide solubility and the cell-penetrating property using Innovagen peptide solubility calculator (https://pepcalc.com/) and CPPpred (http://bioware.ucd.ie/ compass/biowareweb/Server pages/ cpppred.php), respectively. The CPP score is given within the range of $0-1$, wherein the peptides with the score of $>0.5$ are suggestive of better cell penetration. This procedure resulted in four CPPs. Two peptides, VRF005 and VRF007, were selected on the basis of high CPP score, amphiphilicity, and solubility for modeling and experimental validation.

The designed and enriched peptides surpassing all the validation criteria were submitted to I-TASSER server to model the three-dimensional structure. The model having a high confidence score (c-score) signifies higher confidence. Hence high confidence c-score was chosen and further validated for stereochemical properties using Ramachandran plot generated by Procheck. The models having the residues in the outlier regions were optimized by executing the energy minimization script using Modeller 9.15. The models with least DOPE (Discrete Optimized Protein Energy) score were chosen as reliable and were revalidated using Procheck. The designed, modeled, and minimized peptides were further taken for molecular dynamic (MD) simulation studies to study their structural stability. The peptides were preprocessed and optimized using the Schrodinger protein preparation wizard before starting up with an MD production run. The simulation was commenced using Optimized Potential for Liquid Simulations (OPLS) 2005 force field by solvating the cubic system using a Transferable Inter Molecular Potential 3P (TIP3P) water model. The system was neutralized by adding counter ions and energy minimized using OPLS 2005 force field. SHAKE algorithm was used to restrain the geometry of water molecules, bond lengths, and angles of heavy atoms. Periodic boundary conditions were set to simulate a continuous system. The system was further equilibrated using the constant Number, Pressure and Temperature (NPT) ensemble by setting the temperature and pressure parameters to $300 \mathrm{~K}$ and $1.0 \mathrm{bar}$, respectively. Nose-Hoover chain and Martyna-Tobias-Klein were chosen as a coupling algorithm for temperature and pressure, respectively. The equilibrated system was then simulated for a production run of 100 nanoseconds (ns) with a time step of 2 femto seconds (fs), and the trajectories were recorded at every 4.8 pico seconds (ps). The final trajectories were analyzed to perform a collective study on the backbone deviations of the atoms, ie, root mean square deviations convergence, residue fluctuations (root mean square fluctuations), and structure compactness (radius of gyration) throughout the production run of $100 \mathrm{~ns}$ to obtain an insight of the secondary structure stability of these modeled peptides.

\section{Membrane-based simulation for shortlisted peptides}

The peptides that had been shortlisted from the abovementioned analysis were further subjected to membrane simulations using the Desmond module of Schrodinger using OPLS 2005 force field. The peptides were positioned in the phosphatidylcholine (POPC) lipid bilayer membrane system using the OPM server. The area per lipid for POPC lipid bilayer was $65 \AA^{2}$ as reported earlier. ${ }^{15-18}$ The membrane model system prepared with all the three peptides was integrated at the center of the lipid bilayer and water molecules (TIP3P) sparring at a maximum edge distance of $10 \AA$ from solute atoms.

Initial minimization of the system was performed with a convergence threshold value of $1.0 \mathrm{kcal} \mathrm{mol}^{-1} \AA^{-1}$ so as to provide the positional equilibration to all the atoms. The next minimization with and without solute restraints was performed using Berendsen thermostat at temperature $10 \mathrm{~K}$ for $12 \mathrm{ps}$ (pico seconds). This was followed by the equilibration step with the NPT ensemble using Berendsen barostat at $1 \mathrm{~atm}$ pressure for $12 \mathrm{ps}$. The temperature of the system was gradually increased to $300 \mathrm{~K}$ with restraints on solute heavy atoms and without any restrain for next 24 ps using Berendsen NPT ensemble. The PME method used for coulombic consideration with threshold and a cutoff value of $10 \AA$ was used for the estimation of nonbonded solute-solvent and solventsolvent interactions, with pressure and temperature of the system maintained at $1.013 \mathrm{~atm}$ and $300 \mathrm{~K}$, respectively. The Matrix SHAKE algorithm was employed for the reorientation of hydrogen bonds, and the integration step for the calculation 
was fixed at 2 fs (femto seconds). Finally, simulation was carried out for $500 \mathrm{~ns}$ (nano seconds) and the trajectory frames were generated at an interval of $4.7 \mathrm{ps}$ for all the systems and were analyzed using Visual Molecular Dynamics.

\section{Peptide synthesis}

Peptides, VRF005 (KKKWFETWFTEWPKKKK) and VRF007 (KDRPIFQLNTSYWEMGA), were synthesized using solid state synthesis and procured from M/s. Gene Script (https://www.genscript.com/) with an HPLC purity of more than $95 \%$. $\mathrm{N}$ terminal of the peptide was labeled with fluorescein isothiocyanate (FITC).

\section{Secondary structure stability and surface zeta potential analysis of peptides}

Far-ultraviolet (UV) circular dichroism (CD) spectra of peptides, VRF005, VRF007 (500 nM), and gelatin (100 $\mu \mathrm{g}$ in distilled water, $\mathrm{pH}$ 7.0), were recorded on a spectropolarimeter (J810; Jasco International Co., Ltd., Tokyo, Japan) using a $0.1 \mathrm{~cm}$ path length quartz cuvette at $37^{\circ} \mathrm{C}$. Spectra of VRF005 and VRF007 were recorded from $260 \mathrm{~nm}$ to $190 \mathrm{~nm}$ at two different temperatures $\left(4^{\circ} \mathrm{C}\right.$ and $\left.37^{\circ} \mathrm{C}\right)$ at a scan rate of $50 \mathrm{~nm} / \mathrm{min}$ ). Further the interaction of peptide (VRF005) with gelatin was studied by incubating $500 \mathrm{nM}$ of peptide and $100 \mu \mathrm{g}$ of gelatin. The CD measurements were recorded in triplicates.

The stability of the peptide was analyzed in corneal epithelial tissue lysate prepared from the corneal epithelial tissues collected from subjects undergoing photorefractive corrections (ethics no. 489-2015-P). Six corneal epithelial tissues were collected from three subjects (oculus sinister and oculus dextrus). Tissues were lysed using RIPA buffer. Proteins were estimated using bicinchoninic acid (BCA) method as mentioned in the manufacturer's protocol. Briefly, $1 \mu \mathrm{M}$ of peptides (VRF005 and VRF007) was incubated with $20 \mu \mathrm{g}$ and $50 \mu \mathrm{g}$ of corneal epithelial lysate for a period of 2 hours and 24 hours. Peptide incubated with RIPA buffer served as negative control. SDS-PAGE was carried out for analyzing the degradation of FITC-labeled peptides.

Peptide at $1 \mu \mathrm{M}$ concentration was run on $16 \%$ native PAGE for studying peptide aggregation. The aggregation of the peptides (VRF005 and VRF007) at pH 2, 4, 7, and 10.5 was further validated using Zetasizer Nano ZS (Malvern Instruments, Malvern, UK) equipped with a $4 \mathrm{~mW} \mathrm{He-Ne}$ laser operating at $633 \mathrm{~nm}$. The peptide concentration was kept as $1 \mu \mathrm{M}$. Dip cell cuvette with a $1 \mathrm{~cm}$ light path was used, and the scattered light intensities were collected at an angle of $173^{\circ}$ for surface potential measurement, and clear disposable cells were used for zeta size measurements.

\section{Characterization of primary corneal epithelial cells and peptide uptake in primary corneal epithelial cells and fungal cells}

Corneal epithelial tissues were collected from subjects undergoing refractive error correction (ethics no. 489-2015-P) surgery with prior consent and processed for primary human corneal epithelial cells as reported earlier. ${ }^{19}$ The tissues were mechanically disrupted to form a single cell suspension and were plated in collagen-coated plates in DMEM/F-12 medium with HEPES buffer, containing sodium pyruvate and l-glutamine: $50 \mathrm{U} / \mathrm{mL}$ penicillin and $50 \mu \mathrm{g} / \mathrm{mL}$ streptomycin (Thermo Fisher Scientific, Waltham, MA, USA). Once the cells became attached, the cell cycle analysis was performed using propidium iodide and flow cytometry as mentioned in the manufacturer's protocol.

Cells were lysed with RIPA buffer and were separated on an SDS-PAGE at $100 \mathrm{~V}$ in electrophoresis buffer $(25 \mathrm{mM}$ Tris, $190 \mathrm{mM}$ glycine, and $0.1 \%$ SDS). The proteins were separated and transferred to polyvinylidene difluoride (PVDF) membrane (GE Healthcare Bio-Sciences AB, Uppsala, Sweden) using semidry transblot apparatus (Hoefer, Holliston, MA ,USA) at $1.50 \mathrm{~mA} / \mathrm{cm}^{2}$. After transferring, the membrane was blocked for 1 hour at $25^{\circ} \mathrm{C}$ in $5 \%$ $(\mathrm{w} / \mathrm{v})$ nonfat dry milk (NFDM) powder in TBST $(20 \mathrm{mM}$ Tris- $\mathrm{HCl} \mathrm{pH} \mathrm{7.5,} 150 \mathrm{mM} \mathrm{NaCl}$, and $0.1 \%$ Tween 20). The membrane was washed with TBST and incubated at $4^{\circ} \mathrm{C}$ overnight with the following antibodies: claudin 1 (Cell signaling, Danvers, MA, USA), alpha catenin (Cell signaling), E-cadherin (Cell signaling), and ZO2 (Cell signaling). Each antibody was 1,000-fold diluted in either 5\% (w/v) BSA (Hi Media, Mumbai, India) or NFDM in TBST. After overnight incubation, the membrane was washed thrice for 5 minutes with TBST and further incubated in the corresponding HRP-conjugated anti-rabbit and anti-mouse secondary antibody. The secondary antibodies used were diluted to 10,000 -fold in 5\% NFDM (w/v) in TBST. After incubation, the membrane was again washed thrice for 5 minutes with TBST. HRP activity was detected using HRP substrate (catalog no. 1705061; Bio-Rad Laboratories Inc., Hercules, CA, USA) in Bio-Rad Gel Documentation system (Protein Simple, Biorad Hercules, CA, USA).

Peptide uptake experiments were performed after the characterization of the corneal epithelial cells. Peptides were dissolved at a stock concentration of $1 \mathrm{mM}$ in distilled water, and $1 \mu \mathrm{M}$ of VRF005 and VRF007 was incubated with primary corneal epithelial cells to study the intracellular 
localization. After 1-hour incubation, the cells were washed with PBS and visualized through fluorescence microscopy using FITC filter. Muller glial cells (MIOM1 - a gift from Prof GA Limb; UCL Institute of Ophthalmology, London, UK), MCF7-ATCC (breast epithelial tumor cells), and NCC-Rb51-Riken (retinoblastoma tumor cells) were used as controls for the experiments.

Similarly, Candida albicans and F. solani cultures were grown for 12 hours in yeast nitrogen broth (YNB), and the population was adjusted to $1.5 \times 10^{5}$ colony-forming unit (CFU)/ $\mathrm{mL}$, and $10 \mu \mathrm{M}$ of VRF005 and VRF007 was incubated with $C$. albicans and $F$. solani cultures for a period of 1 hour and was visualized for the intracellular localization using fluorescence microscopy (Axio Zeiss, Carl Zeiss, Oberkochen Germany).

Antimicrobial activity of peptides was predicted using an online server Antimicrobial Peptide Database:3 (http://aps. unmc.edu/AP/prediction/prediction_main.php). The antifungal efficacy of peptides (VRF005 and VRF007) was carried out against standard strains of C. albicans (ATCC-90028) and $F$. solani. Minimum inhibitory concentration (MIC) of peptides, VRF005 and VRF007, was performed against C. albicans strain at serial onefold dilution in Sabouraud's dextrose agar (SDA) media. Medium alone was used as control. A volume of $100 \mu \mathrm{L}$ from each serially diluted cuvette was spread on SD agar plate. The plates were incubated at $37^{\circ} \mathrm{C}$ for 48 hours. The appropriate dilution factor was multiplied to attain the final viable cell concentration. A total number of colonies were counted, and the graph was plotted as reported earlier. ${ }^{20}$

\section{Killing kinetics of peptides}

Antifungal activity of native VRF007 and VRF005 was performed against fresh culture of $C$. albicans $\left(1-5 \times 10^{5}\right.$ cells $\left./ \mathrm{mL}\right)$ and $F$. solani $\left(0.4-5 \times 10^{5}\right.$ cells $\left./ \mathrm{mL}\right)$. Treatment concentration of the peptides was 10-fold higher than their respective MIC values. Natamycin $(32 \mu \mathrm{g} / \mathrm{mL})$ was used as positive control. The experiments were performed in duplicate and were repeated at least three times. The plates were incubated at $25^{\circ} \mathrm{C}$, and readings were taken at predetermined time intervals: (30 minutes, 1 hour, 2 hours, 4 hours, 24 hours) in spectrophotometer $(600 \mathrm{~nm})$. Then, the graph was plotted using GraphPad Prism 6.0 (GraphPad Software, Inc., La Jolla, CA, USA).

Microdilution plates (24-well plates) coated with soft gel and soft gel cross-linked with VRF005 $(10 \mu \mathrm{M})$ were used. C. albicans $\left(1-5 \times 10^{6}\right.$ cells $\left./ \mathrm{mL}\right)$ and $F$. solani $\left(0.4-5 \times 10^{6}\right.$ cells $\left./ \mathrm{mL}\right)$ were inoculated on soft gel and VRF005-cross-linked soft gel. The plates were incubated at $25^{\circ} \mathrm{C}$. The readings were taken at predetermined time intervals: (30 minutes, 1 hour, 2 hours, 4 hours, 24 hours) in spectrophotometer $(600 \mathrm{~nm})$. Then, the graph was plotted using GraphPad Prism 6.0.

\section{Characterization of gelatin hydrogel and CPP delivery}

Hydrogels were prepared using type B gelatin (Sigma-Aldrich Co., St Louis, MO, USA). Two different concentrations of gelatin gels were prepared $(100 \mathrm{mg} / \mathrm{mL}$ and $50 \mathrm{mg} / \mathrm{mL})$ using $0.8 \mu \mathrm{g} / \mathrm{mL}$ of glutaraldehyde as cross-linker and incubated at $4^{\circ} \mathrm{C}$ for 4 hours for gelation and cross-linking. For preparing different stiffnesses of hydrogel, two different concentrations of gelatin were used. Higher concentration of gel $(100 \mathrm{mg} / \mathrm{mL})$ was referred to as hard gel, and lower concentration $(50 \mathrm{mg} / \mathrm{mL})$ was referred to as soft gel. The cross-linked gelatin hydrogels were immersed in a $50 \mathrm{mM}$ glycine aqueous solution under agitation for 1 hour to block the residual aldehyde groups of glutaraldehyde, followed by two washes with double-distilled water for 1 hour. Similarly, for the cross-linking of peptide (VRF005), 56.6 $\mu \mathrm{g}$ of peptide was cross-linked with gelatin using glutaraldehyde as crosslinker. The hydrogels were freeze-dried and used for scanning electron microscopy (SEM) analysis using field-emission gun (FEG)-SEM (JSM-7600F; JEOL Ltd., Tokyo, Japan). The pore size of the hydrogel was calculated using ImageJ.

\section{Swelling behavior}

The hydrogels were immersed in deionized water at room temperature. The samples were taken out from deionized water at selected time intervals, wiped with wet tissue paper to remove surface droplets, weighed, and placed back in deionized water. The swelling ratio $\mathrm{Q}_{\mathrm{m}}$ was calculated using the following equation, where $\mathrm{W}_{\mathrm{s}}$ is the weight of swollen hydrogels and $\mathrm{W}_{\mathrm{d}}$ is the initial weight of the sample. ${ }^{21}$

$$
\% \text { Swelling }=\frac{\mathrm{W}_{\mathrm{S}}-\mathrm{W}_{\mathrm{d}}}{\mathrm{W}_{\mathrm{d}}} \times 100 \text {. }
$$

\section{Fourier transform infrared (FTIR) spectroscopy analysis}

Soft gelatin hydrogel with and without peptide VRF005 was freeze-dried. The chemical compositions of the hydrogels were identified with infrared spectroscopy (Tensor 27 FTIR; Bruker Optik, GmbH, Germany). The samples were prepared using potassium bromide $(\mathrm{KBr})$ pellet and placed on sample holder, and the spectrum was recorded in absorbance mode in the region between $400 \mathrm{~cm}^{-1}$ and 4,000 $\mathrm{cm}^{-1}$ using deuterated triglycine sulfate detector. 


\section{Peptide release kinetics from gelatin hydrogel}

Gelatin hydrogels of two different stiffnesses (soft and hard gels) and with/without glutaraldehyde cross-linker were prepared. The hydrogels were incorporated with $56.6 \mu \mathrm{g}$ of peptide (VRF005). The standard graph for FITC-labeled peptide was made at $488 \mathrm{~nm}$ with different concentrations $(1 \mu \mathrm{g}, 5.6 \mu \mathrm{g}, 11.3 \mu \mathrm{g}, 16.9 \mu \mathrm{g}$, and $22.6 \mu \mathrm{g})$. The release kinetics of peptide from hydrogel was studied in a regular interval, and $500 \mu \mathrm{L}$ of fresh PBS/deionized water was replaced in the hydrogel. The peptides released into the PBS were quantified using UV-visible spectrophotometer at $488 \mathrm{~nm}$. The amount of peptide released was measured using the peptide standard graph. The antifungal activity of gelatin and gelatin-cross-linked peptides (VRF005) were measured using time-killing kinetics as mentioned earlier.

\section{Analysis of corneal epithelial cell adhesion on hydrogel}

Primary corneal epithelial cells were seeded on both hard and soft hydrogels for 24 hours. Then, the cells are fixed with $4 \%$ paraformaldehyde for 10 minutes, washed three times with $1 \times$ PBS, and permeabilized with $0.1 \%$ Triton-X for 5 minutes, followed by $1 \times$ PBS wash. Cells were further stained with FITC-phalloidin (Cytoskeleton Inc., Denver, CO, USA), and the cell nucleus was counterstained with Hoechst staining; furthermore, they were imaged with a fluorescence microscope (Axio Observer; Carl Zeiss Meditec AG, Jena, Germany).

\section{Statistical analyses}

All data were presented as mean and SD of at least three independent experiments. Statistical analysis was performed using the GraphPad Prism 6.0 statistical program. One-way ANOVA was followed by Bonferroni post hoc test when compared among the groups for the same experimental duration. Significance was defined by $P$-values of $<0.05$.

\section{Results}

\section{Designing and modeling of CPPs}

CPPs were designed from conserved human corneal proteome and $F$. solani proteome as shown in Figure S1A. We selected two CPPs for experimental validations based on the CPP score, amphipathicity and solubility, out of four CPPs came as results. The net charge and hydrophobicity ratio were calculated and are shown in Figure S1B. Briefly, VRF005 had a net charge of +5 , whereas VRF007 had no charge. Higher grand average of hydropathicity (GRAVY) score of VRF007 (-0.782) is relatively more hydrophobic than VRF005 (-2.024). Peptides were modeled using I-TASSER server. VRF005 had a c-score value of -0.37 , whereas the c-score was -1.45 for VRF007. The modeled and validated peptides were further taken for MD simulation to study the secondary structure stability. The final trajectories of peptides showed stability as shown in Figure S2A and B. MD analysis of VRF005 peptide exhibited a stable structure between $70 \mathrm{~ns}$ and $100 \mathrm{~ns}$. Furthermore, the peptide had an $\alpha$-helical structure and flexible amino acid residues throughout the simulation conditions (Figure S2A). VRF007 showed a stable structure between $30 \mathrm{~ns}$ and $100 \mathrm{ns,}$ and the partial $\alpha$-helical structure was changed to random coil during this time period (Figure S2B). The Ramachandran plots showed that both peptides were in the allowed region, VRF005 (Figure S3) and VRF007 (Figure S4). The structure of the peptides was further studied using CD spectroscopy.

\section{Characterization of peptide using CD spectrophotometer and zeta sizer}

Endocytosis and translocation of peptides are dependent on their secondary structure, which are also influenced by temperature. Hence, we studied secondary structure of peptides using $\mathrm{CD}$ spectra at two different temperatures, $37^{\circ} \mathrm{C}$ and $4^{\circ} \mathrm{C}$ (Figure 1A). VRF007 showed high-intensity negative band at $222 \mathrm{~nm}$ and $208 \mathrm{~nm}$ and positive intensity band at $200 \mathrm{~nm}$ at $37^{\circ} \mathrm{C}$. All three vibrations were drastically reduced at $4^{\circ} \mathrm{C}$. However, VRF005 showed a negative band at $200 \mathrm{~nm}$ which did not vary with changes in temperature. Further, the peptides were characterized using native PAGE and dynamic light scattering for its aggregation property. VRF007 showed three bands in the native PAGE representing different aggregations, whereas VRF005 showed single band in native PAGE (Figure 1B). The predicted molecular weight of the peptide was validated using 16\% SDS-PAGE and found to be around $2.5 \mathrm{kDa}$. The zeta potential of the peptides (VRF005 and VRF007) was $+10 \mathrm{mV}$ at both the $\mathrm{pH} 2$ and $\mathrm{pH} 7$, whereas at $\mathrm{pH} 10.5$ it was found to be $-40 \mathrm{mV}$ (Figure 1C). The average size of VRF005 aggregation was maintained at $1,200 \mathrm{~nm}$ across the entire range of $\mathrm{pH}$ (Figure 1D). Interestingly, VRF007 was found to aggregate at different $\mathrm{pH}(2,4,7$, and 10.5), and VRF007 exhibited different average size aggregation of $500 \mathrm{~nm}, 2 \mu \mathrm{m}$, and $3 \mu \mathrm{m}$ at $\mathrm{pH} 2,4$, and 7, respectively (Figure 1E). At $\mathrm{pH} 7$, VRF007 showed $68 \%$ of population within $200 \mathrm{~nm}$ size and $29 \%$ within $400-600 \mathrm{~nm}$. In an acidic pH, VRF007 had 90\% of its population in the size of $400 \mathrm{~nm}$ suggesting the effect of $\mathrm{pH}$ on the aggregation. The amount of net charge and aggregation determines the crucial property of peptides such as solubility, membrane permeability, and membrane partitioning. Further, the potential of the peptide for cell penetration was predicted using membrane-based simulation followed by cellular uptake studies in corneal epithelial cells. 
A
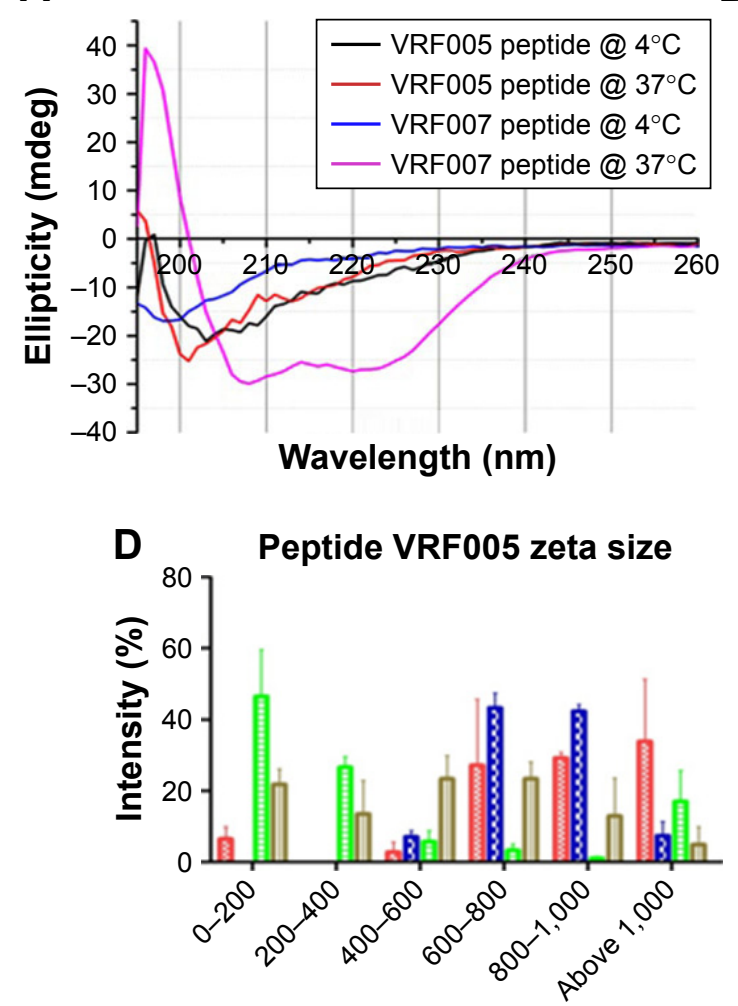

Size $(\mathrm{nm})$

$\begin{array}{|ll|}\square \text { VRF005 at pH } 2 & \text { VRF005 at pH } 4 \\ \square \text { VRF005 at pH } 7 & \text { WRF005 at pH 10.5 }\end{array}$

B
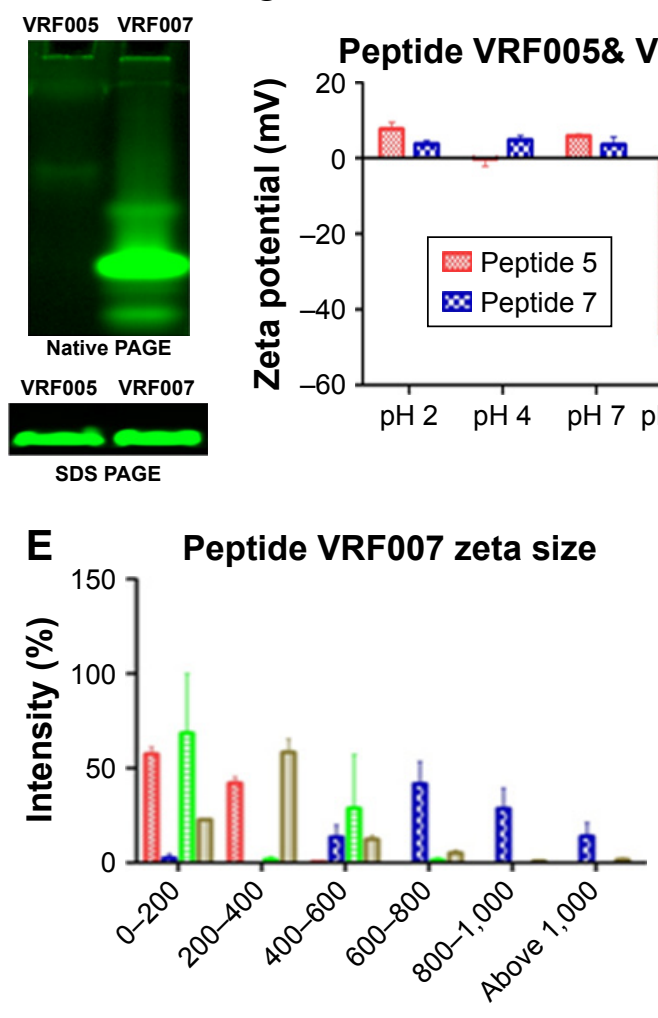

Size $(\mathrm{nm})$

\begin{tabular}{|ll|}
$\square$ VRF007 at pH 2 & \&RF007 at pH 4 \\
$\square$ VRF007 at pH 7 & 四 VRF007 at pH 10.5 \\
\hline
\end{tabular}

Figure I (A) CD spectroscopy of peptides (VRF005 and VRF007) at two different temperatures, $4^{\circ} \mathrm{C}$ and $37^{\circ} \mathrm{C}$. The experiments were performed in triplicate. (B) Native and SDS-PAGE of peptides (VRF005 and VRF007). (C) Zeta potential of peptides (VRF005 and VRF007). (D, E) Dynamic light scattering of peptides (VRF005 and VRF007) at different $\mathrm{pH}$ levels.

Abbreviation: $\mathrm{CD}$, circular dichroism.

\section{Molecular simulation of VRF005 and VRF007 for membrane penetration}

The average thickness of lipid bilayer in the presence of VRF005 and VRF007 was about $36.067 \AA$ and $38.719 \AA$ Á, respectively. It was noted that VRF007 peptide showed higher perturbation for the lipid bilayer during the simulation. The area per lipid value for peptides VRF005 and VRF007 along the bilayer was $73.305 \AA^{2}$ and $69.460 \AA^{2}$, respectively (Figure 2A-C). Hence, both the peptides (VRF005 and VRF007) had the ability to penetrate the membrane system. This observation was further validated by uptake studies.

\section{Peptide uptake by corneal epithelial cells and fungal cells}

SEM of corneal epithelial tissue confirmed the presence of squamous epithelium, wing cells, and basal cells (Figure S5A), and $98 \%$ of the cells were in $\mathrm{G}_{0}-\mathrm{G}_{1}$ phase of cell cycle. The predominant presence of cells in this phase is a characteristic feature of corneal epithelial cells (Figure S5B).
Expression of corneal epithelial cell markers, claudin 1, alpha catenin, $\mathrm{ZO} 2$, and E-cadherin, was observed in cells isolated from the tissues (Figure S5C). The uptake study showed that VRF005 and VRF007 were able to penetrate corneal epithelium and C. albicans, but VRF005 alone showed uptake in F. solani (Figure 3A, C, D).

\section{Evaluation of peptide stability, toxicity, and antifungal activity}

Stability of peptides was performed in different protein concentrations $(10,20$ and $30 \mu \mathrm{g})$ obtained from corneal tissue to understand the time course of degradation inside the cellular environment. Both the peptides were stable for 2 hours at both concentrations (Figure S5D). However, VRF005 was stable in corneal epithelial tissue lysate at $25 \mu \mathrm{g}$ concentration for 24 hours but got degraded at $50 \mu \mathrm{g}$ concentration, whereas VRF007 peptide was degraded after 24 hours at both $25 \mu \mathrm{g}$ and $50 \mu \mathrm{g}$ concentrations (Figure S5E). The peptides did not 


\section{A}

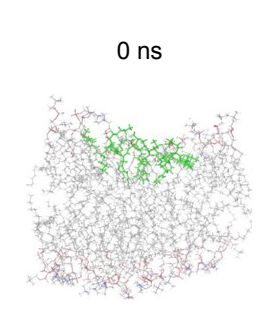

VRF005

$300 \mathrm{~ns}$

500 ns

B

VRF007

$300 \mathrm{~ns}$
500 ns
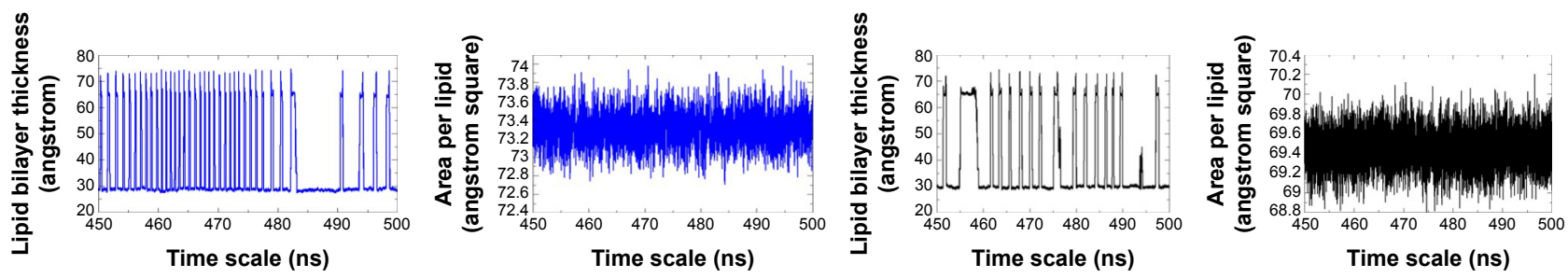

C

\begin{tabular}{lll}
\hline Parameters & VRF005 & VRF007 \\
\hline $\begin{array}{l}\text { Average thickness of } \\
\text { lipid bilayer }\end{array}$ & $36.067 \mathrm{~A}^{0}$ & $38.719 \mathrm{~A}^{0}$ \\
Area per lipid $\left(65 \mathrm{~A}^{02}\right)$ & $73.305 \mathrm{~A}^{02}$ & $69.460 \mathrm{~A}^{02}$ \\
\hline
\end{tabular}

Figure 2 (A, B) Structural snapshots of MD simulations' average thickness of lipid bilayer, and area per lipid measured with respect to time of peptide VRF005 at 0 ns, 300 ns, and $500 \mathrm{~ns}$ in the presence of POPC lipid bilayer. (C) Table showing the values of analysis of peptides in POPC membrane.

Abbreviations: MD, molecular dynamic; POPC, phosphatidylcholine.

show any uptake in retinoblastoma cell line NCC-RB51 (Figure 3B), MIOM1 and MCF7 cells (Figure S6A and B), suggesting the specificity of designed peptides towards corneal epithelial cells.

Primary corneal epithelial cells were treated with different concentrations $(1 \mu \mathrm{M}, 5 \mu \mathrm{M}$, and $10 \mu \mathrm{M})$ of peptides for a period of 24 hours, and cell viability was performed by MTT assay. Our data showed that the peptides were nontoxic and more than $80 \%$ of the cells were viable for the period of 24 hours at $1 \mu \mathrm{M}$ concentration (Figure S5F).

The potential antifungal activity of the peptides was validated through colony-forming assay and time-killing kinetics. VRF007 and VRF005 exhibited antifungal activity at MIC of $1 \mu \mathrm{g} / \mathrm{mL}$ (Figure $4 \mathrm{~A}$ ), whereas the conventional antifungal drug natamycin was effective only at $64 \mu \mathrm{g} / \mathrm{mL}$. The colony-forming ability of C. albicans decreased substantially
A

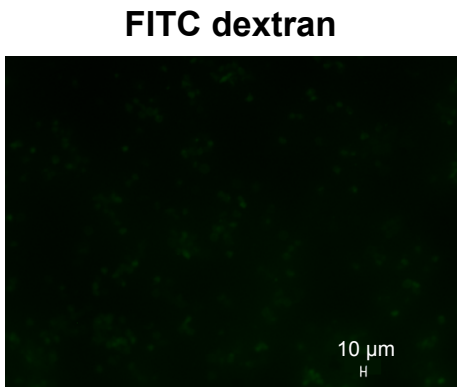

B

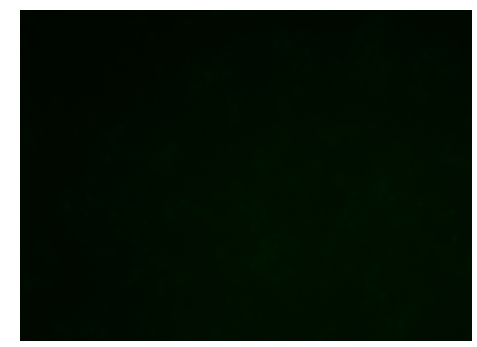

VRF005
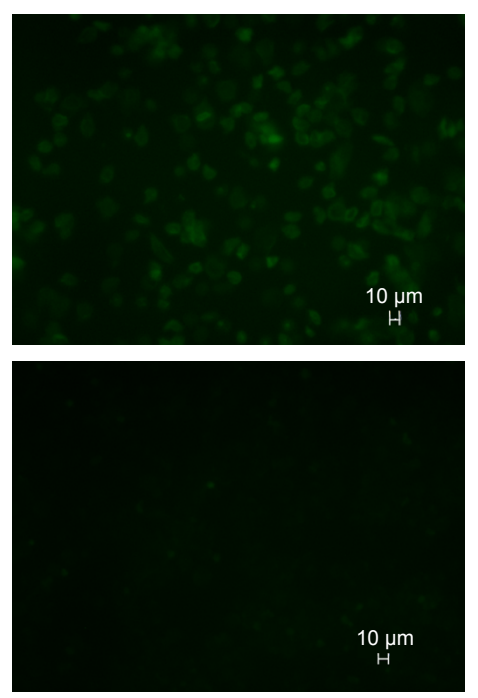

VRF007
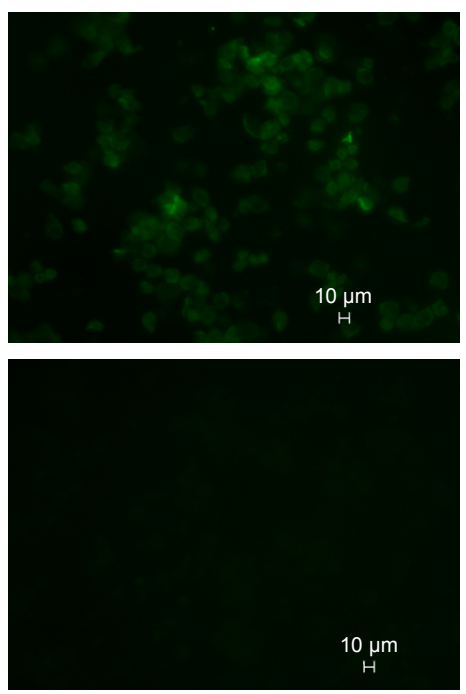

Figure 3 (Continued) 
C

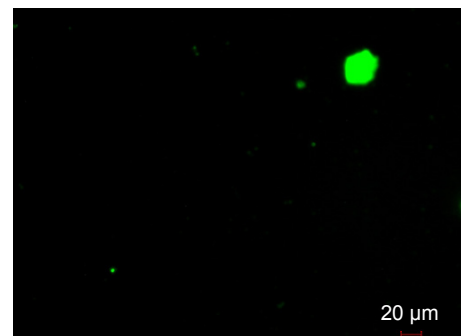

D

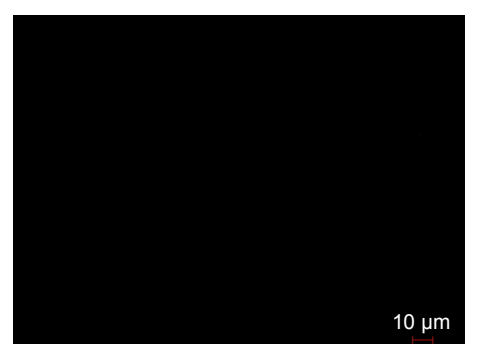

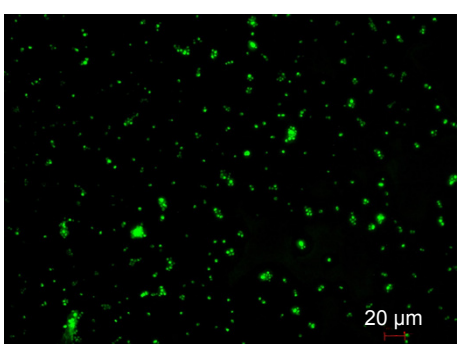
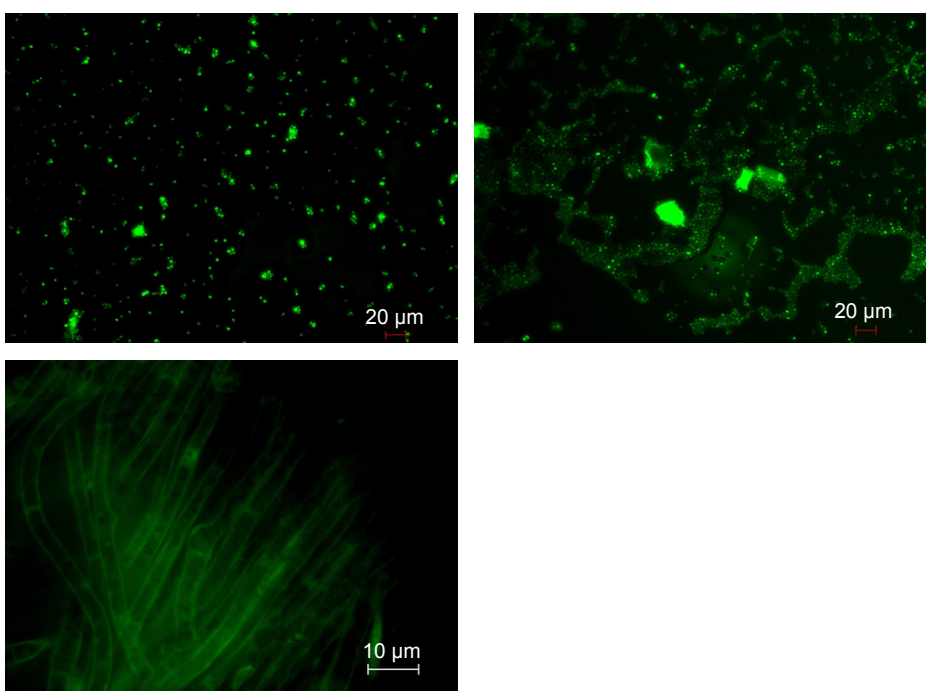

Figure 3 (A) Uptake of peptides, VRF005 and VRF007, at I $\mu$ M concentration by primary corneal epithelial cells. FITC dextran was used as negative control. (B) VRF005 and VRF007 uptake at I $\mu$ M concentration by NCC-RB5I cell line. (C) Peptide uptake, VRF005 and VRF007, by C. albicans at I $\mu$ M concentration. (D) VRF005 uptake in F. solani. Abbreviations: C. albicans, Candida albicans; FITC, fluorescein isothiocyanate; F. solani, Fusarium solani.

when treated with peptides. Killing kinetics of the peptide at 10-fold higher concentration than their respective MIC values showed drastic decrease in the growth of the fungus $F$. solani and C. albicans for a period of 4 hours by both peptides
(Figure 4B and C). However, after 4 hours, the activity of VRF005 was completely lost and increase in the growth of F. solani and C. albicans was observed. Interestingly, VRF007 inhibited the growth of $C$. albicans and F. solani
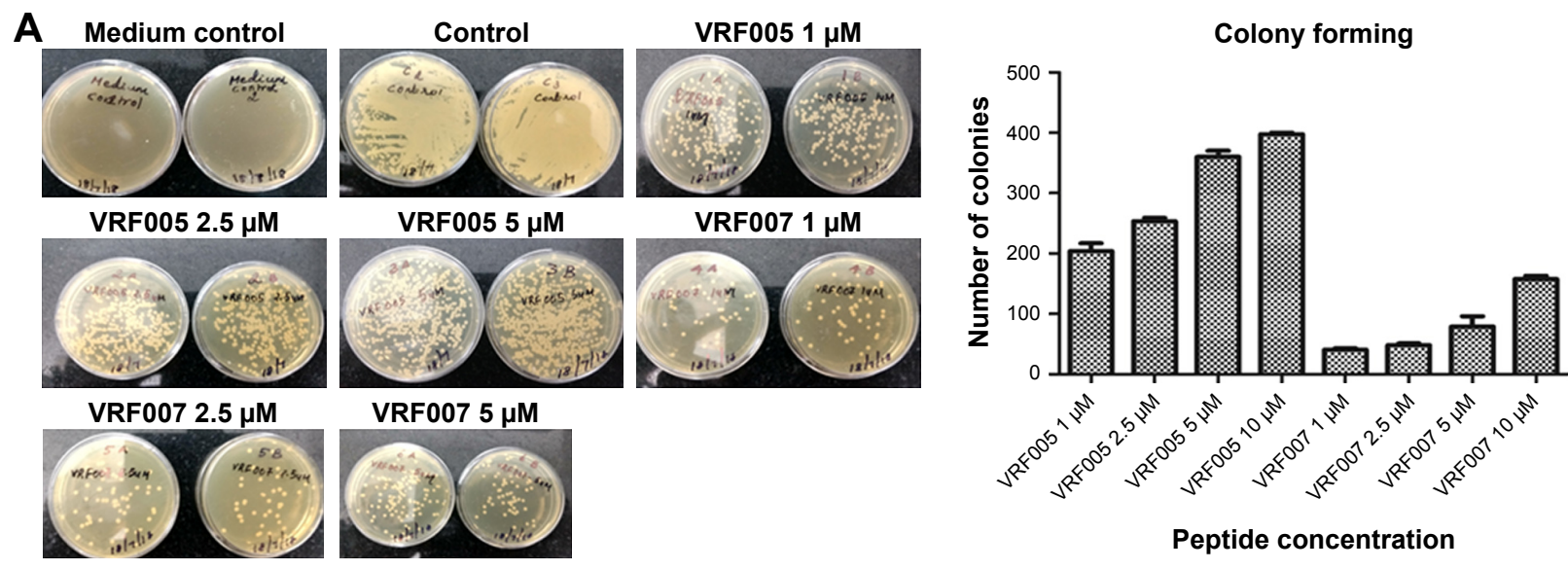

Peptide concentration

B

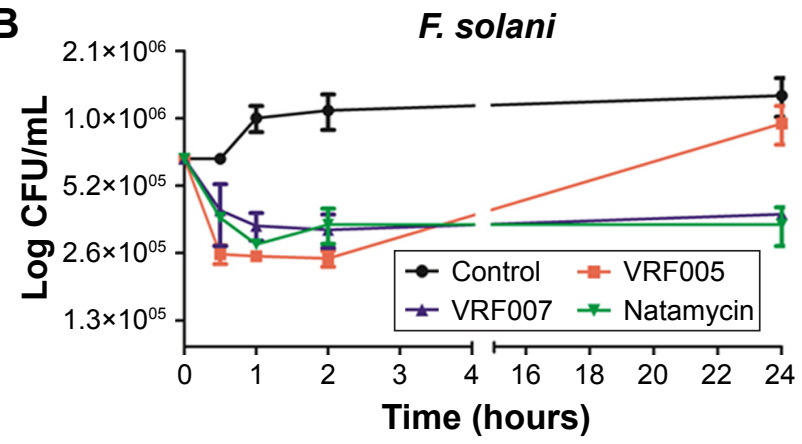

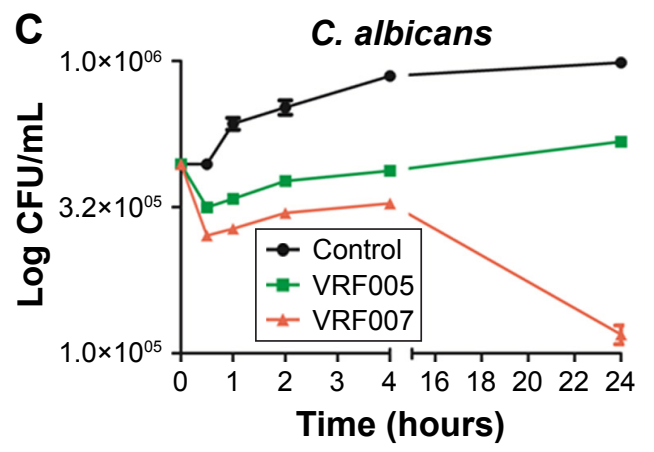

Figure 4 (A) CFU of C. albicans after treatment with different concentrations of peptides, VRF005 and VRF007 (I $\mu \mathrm{M}, 2.5 \mu \mathrm{M}$, and $5 \mu \mathrm{M})$. Graphical representation of number of colonies formed after the treatment (B, C). Killing kinetics of peptides, VRF005 and VRF007, at $10 \mu M$ concentration at different time points for F. solani and C. albicans. Abbreviations: C. albicans, Candida albicans; CFU, colony-forming unit; F. solani, Fusarium solani. 
for 24 hours. The efficacy studies indicated that VRF005 is less effective than the VRF007 even though it was more stable than the later peptide (Figure S5D and S5E). Therefore, hydrogel-mediated delivery could potentially improve the efficacy of VRF005.

\section{Characterization of gelatin hydrogel for peptide delivery}

We used gelatin hydrogel delivery system for sustained release and enhanced antifungal activity of VRF005. UV-visible spectrometry results showed that both the gels were optically transparent between $300 \mathrm{~nm}$ and $700 \mathrm{~nm}$ (Figure 5A). The swelling ratio was considerably altered for the soft gel in the presence of cross-linker where it was not visibly altered for the hard gel in the presence of crosslinker (Figure 5B).

A

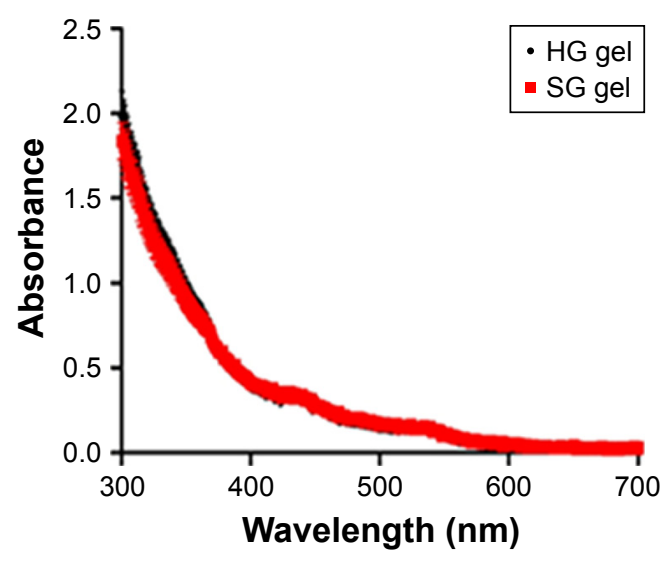

C

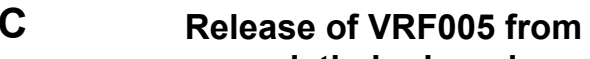
gelatin hydrogel

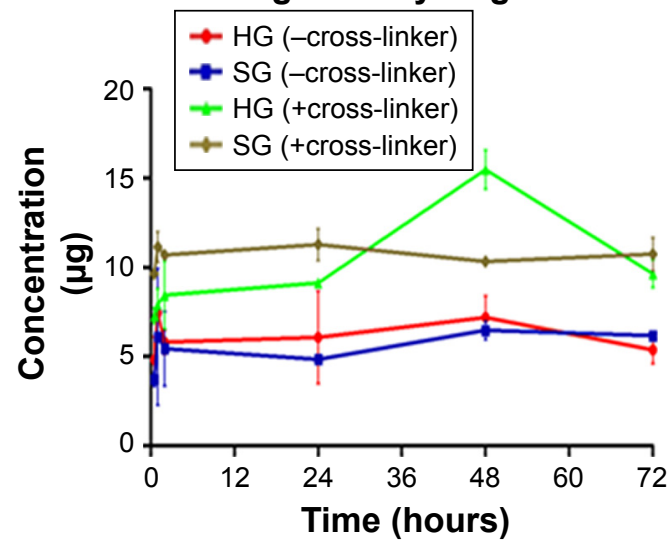

\section{Peptide release kinetics from gelatin hydrogel}

The cumulative release of peptide VRF005 from hard and soft gels was determined by UV spectrophotometry (Figure 5C). A total of $54.6 \mu \mathrm{g}$ and $44 \mu \mathrm{g}$ of VRF005 were released from hard and soft gels with cross-linker out of $56.6 \mu \mathrm{g}$ of the peptides loaded on to the gel. Similarly, $36.7 \mu \mathrm{g}$ and $32.7 \mu \mathrm{g}$ of peptide were released from hard gel and soft gel without cross-linker, respectively, at 72 hours indicating the effect of cross-linker on peptide release.

\section{Cell adhesion in gelatin hydrogel}

Actin (phalloidin) staining of corneal epithelial cells seeded on both hard and soft gel was analyzed after 24 hours of incubation. The cells grown on soft gel exhibited prominent stress fibers (Figure 5D). Therefore, soft gelatin hydrogel was used for VRF005 peptide delivery. VRF005 was cross-linked
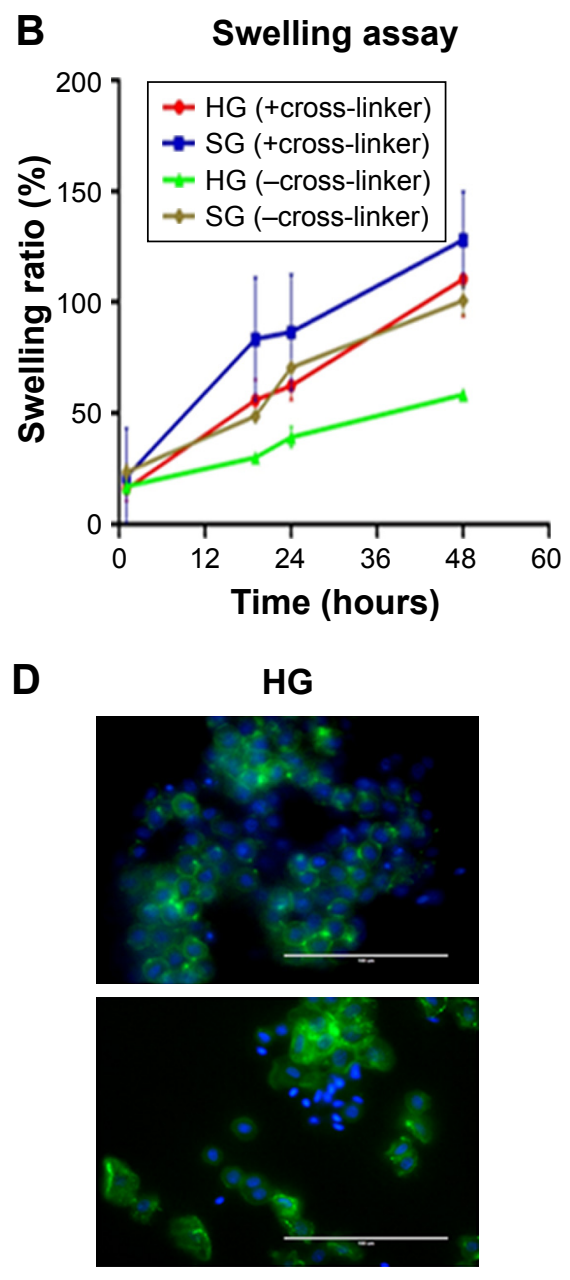

SG

Figure 5 (A) Absorption spectroscopy of HG and SG hydrogels from $300 \mathrm{~nm}$ to $700 \mathrm{~nm}$. (B) Swelling assay of HG and SG hydrogels with and without cross-linker. (C) Release of VRF005 with and without cross-linker from gelatin hydrogel. (D) Corneal epithelial cells on hard gel and soft gel.

Abbreviations: HG, hard gelatin; SG, soft gelatin. 

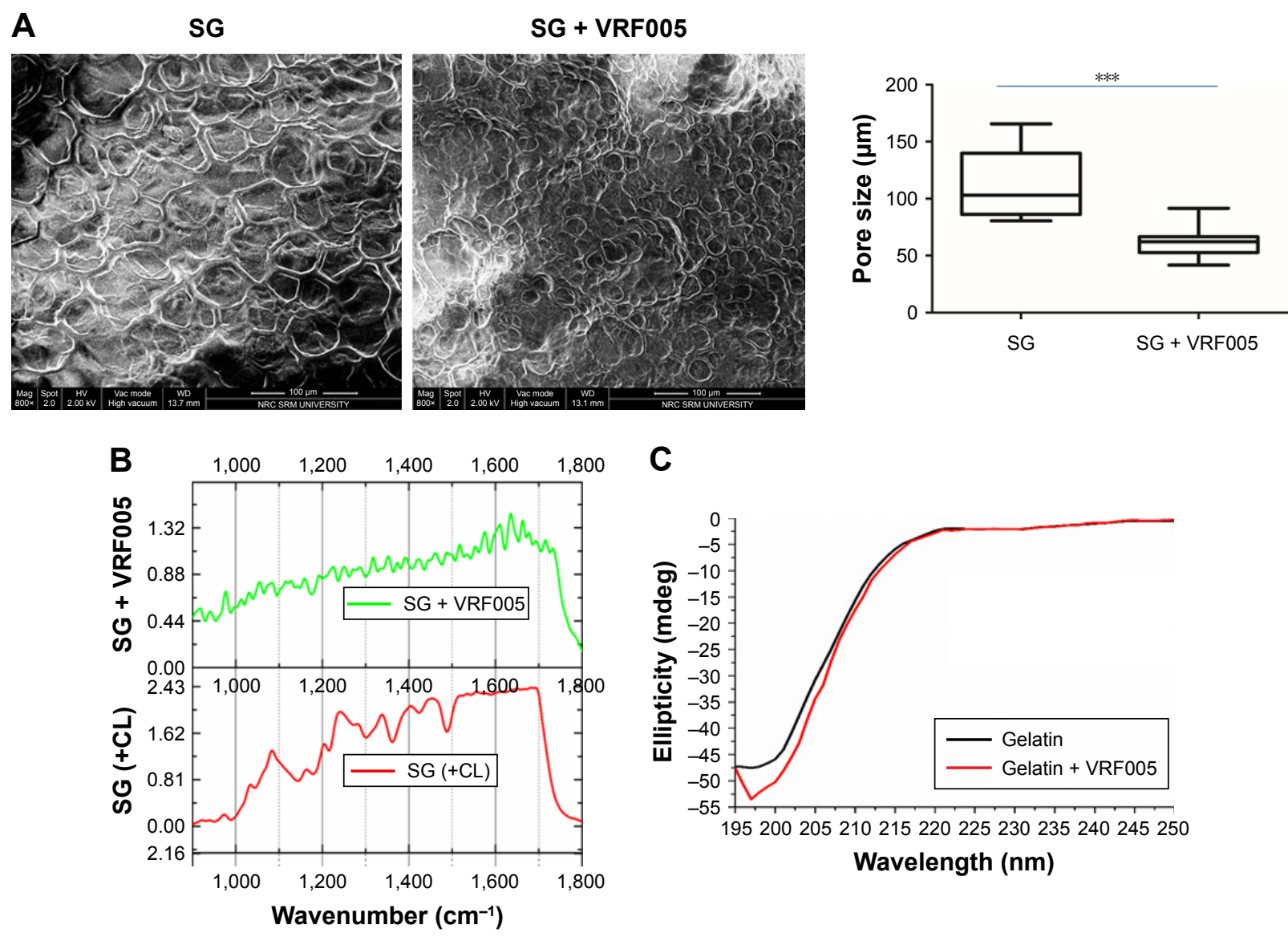

C
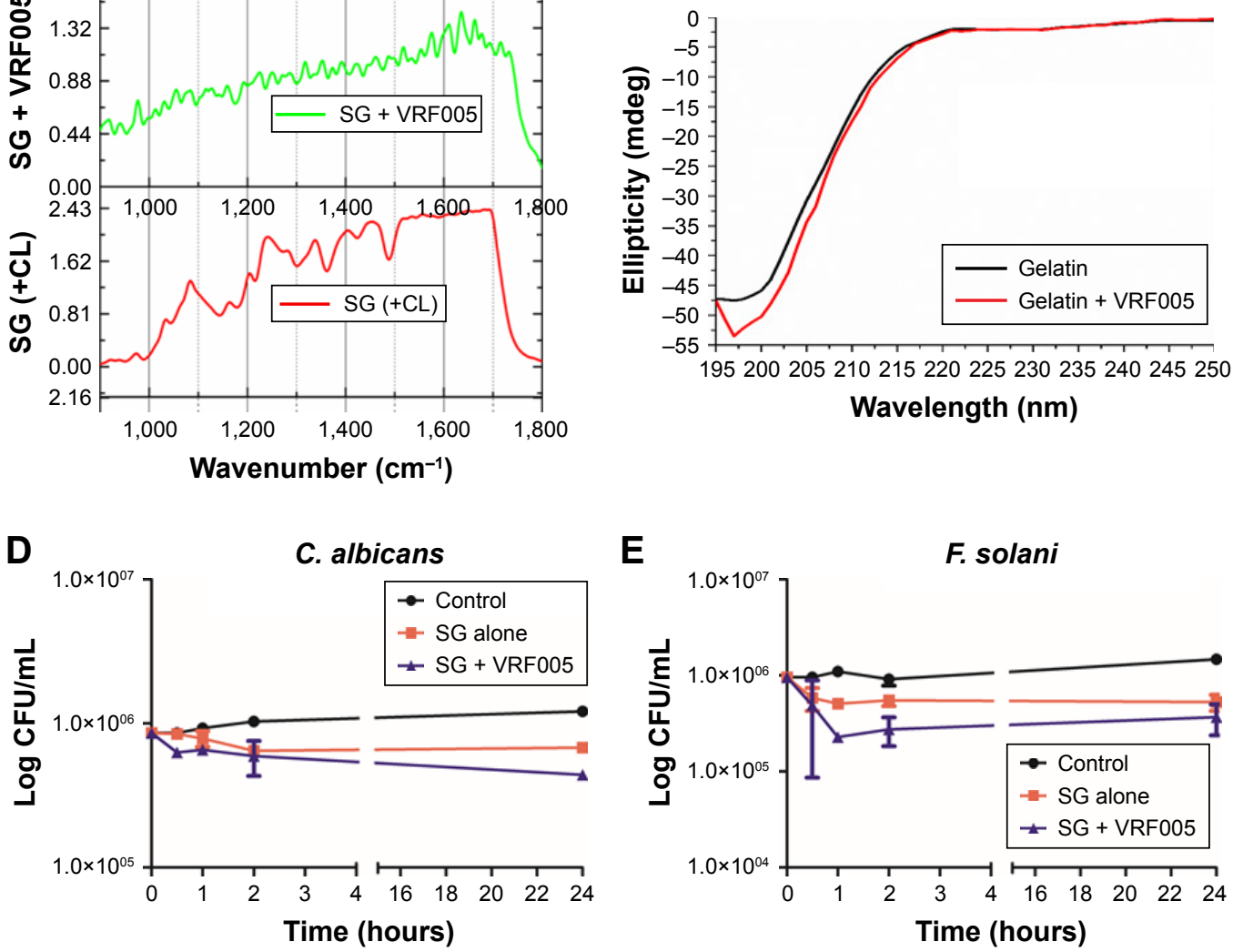

Figure 6 (A) SEM and pore size quantification of SG with and without VRF005. ***P<0.00I. (B) FTIR spectroscopy SG hydrogel with and without peptide VRF005 crosslinking. (C) CD spectroscopy of gelatin and gelatin with peptides (VRF005). Time-killing kinetics of SG hydrogel with and without cross-linking peptide VRF005. (D) C. albicans. (E) F. solani.

Abbreviations: C. albicans, Candida albicans; CD, circular dichroism; CL, crosslinker; F. solani, Fusarium solani; FTIR, Fourier transform infrared; HG, hard gel; SEM, scanning electron microscopy; SG, soft gelatin.

with gelatin hydrogel and examined by SEM. The pore size of soft gelatin hydrogel was on average of $120 \mu \mathrm{m}$ (Figure 6A). The soft hydrogel, after cross-linking with VRF005, the pore size reduced to $50 \mu \mathrm{m}$ (Figure 6A). The cross-linking of the peptide VRF005 with gelatin hydrogel was analyzed using vibrational spectroscopy (Figure 6B). VRF005 encapsulation on gelatin exhibited intense peaks at $1,600 \mathrm{~cm}^{-1}$ and $900 \mathrm{~cm}^{-1}$ compared to gelatin hydrogel (Figure 6B). CD spectra also showed that gelatin has a strong negative trough around $197 \mathrm{~nm}$ and no broad positive band in the $\mathrm{n}-\pi^{*}$ region (Figure 6C). Furthermore, VRF005 peptide addition to soft hydrogels increased the intensity of the negative peak around $200 \mathrm{~nm}$ region (Figure 6C) without altering the structure.

\section{Antifungal activity of peptide released from gelatin hydrogel}

Soft gel was chosen based on the sustained release kinetics of VRF005 and corneal epithelial cell attachment. Soft gel 
cross-linked with VRF005 peptide showed antifungal activity against $C$. albicans and $F$. solani for the period of 24 hours (Figure 6D and E). Hence, the overall antifungal activity of VRF005 was drastically improved through gelatin hydrogel.

\section{Discussion}

Earlier studies have reported the designing of CPP from proteins such as heparin-binding motif of human eosinophil cationic protein, human nuclear body protein, SP140-like protein, and 12 isoforms of annexin, a family of membraneinteracting human proteins. ${ }^{22-24}$ However, there is no report of using the total proteome to design a CPP which would be tissue specific. In this context, we have attempted to design a corneal-specific CPP using subtractive proteomic approach. The tissue specificity of the peptide was validated by the cellular uptake studies. Both VRF005 and VRF007 showed intracellular localization in primary corneal epithelial cells but not in retinoblastoma cell line, breast cancer cell line, and Muller glial cell line (NCC-RB51, MCF-7, and MIOM1 cells), thus confirming their tissue specificity. Interestingly, peptides also showed localization in C. albicans and F. solani. VRF007's secondary structure was altered from $\alpha$-helical structure to random coil, when there was a change in temperature from $37^{\circ} \mathrm{C}$ to $4^{\circ} \mathrm{C}$, whereas VRF005 did not show any structural alterations in secondary structure indicating the stability of VRF005 at both the temperatures. VRF007 showed three bands in native PAGE, whereas VRF005 gave a single band indicating VRF007 aggregation. This was further confirmed by measuring peptide-aggregating sizes in the different ionic strength medium. Antimicrobial peptide has been reported to be influenced by $\mathrm{pH}$, hydrophobicity, and aggregation. ${ }^{25}$

Peptides, VRF005 and VRF007, at $\mathrm{pH} 2-7$ have a lower zeta potential, whereas at $\mathrm{pH} 10.5$ have higher zeta potential which indicated the high degree of stability. However, low zeta potential for VRF007 peptide indicated peptide aggregation. Aggregating peptide also has the potential for antimicrobial activity. ${ }^{26}$ Time-killing kinetics showed drastic reduction in fungal growth $(C$. albicans and $F$. solani). VRF005 lost the activity after 4 hours of treatment, whereas VRF007 maintained the antifungal activity up to 24 hours. The superior antifungal activity of VRF007 peptide could be attributed to its aggregation property. ${ }^{27} \mathrm{We}$ found that VRF005 was comparatively more stable than VRF007. However, the activity was much lower than VRF007. Hence sustained delivery of the peptide VRF005 was needed to improve the activity. Hence, we cross-linked VRF005 peptide with gelatin hydrogel to sustain the release and improve the activity.
FTIR data indicated the cross-linking of peptides with gelatin. The appearance of $1,100 \mathrm{~cm}^{-1}(\mathrm{C}-\mathrm{N}$ of amide III), $1,600 \mathrm{~cm}^{-1}$ (NH amide I), and loss of 1,400 $\mathrm{cm}^{-1}$ (aromatic $\mathrm{C}-\mathrm{C}$ ) in VRF005 indicated encapsulation within gelatin hydrogel. The shift in the following wavenumbers clearly indicated the cross-linking of peptides in the gel. ${ }^{21} \mathrm{CD}$ spectra analysis revealed that peptide VRF005 cross-linked with gelatin hydrogel did not induce any changes in the gelatin's secondary structure. The reduction in pore size of the peptide-cross-linked gelatin hydrogel compared to native gelatin hydrogel indicated that cross-linking of the peptides occurs not only on the surface but also throughout the gel. Corneal epithelial cells showed prominent attachment on soft gelatin hydrogel indicating the preferred stiffness. Soft gel-cross-linked peptide exhibited sustained drug release for 24 hours and improved the activity of VRF005 from 4 hours to 24 hours in both $C$. albicans and $F$. solani. Earlier reports have used gelatin hydrogel for small molecule (antifungal) drug delivery. ${ }^{28}$ To the best of our knowledge, gelatin hydrogel has not been reported for CPP delivery with antifungal activity.

\section{Conclusion}

We used novel subtractive proteomic approach to design tissue-specific CPP. In addition, the CPP also had antifungal activity. The duration of the antifungal activity of the peptide was drastically improved by incorporating in to gelatin hydrogel delivery system which may have clinical relevance. This hydrogel-based delivery would also improve the bioavailability of the drug for a longer duration, potentially reducing the frequency of application necessary for therapeutic use.

\section{Acknowledgments}

JN and AC acknowledge the Department of Biotechnology (DBT), Government of India, for funding (BT/PR14690/ MED/32/496/2015) and fellowship. The authors thank SRM University Nanotechnology Research Center for SEM and Indian Institute of Technology (IIT) Madras for CD spectroscopy. Authors also thank "High performance computing" supported by Science and Engineering Research Board (SERB), Government of India, grant No. YSS/2014/000282. They thank Dr Sailaja Elchuri, Department of Nanobiotechnology, Vision Research Foundation, Sankara Nethralaya campus, for critically reviewing the manuscript and also thank A Samdani, VRF, for proofreading the manuscript.

\section{Disclosure}

The authors report no conflicts of interest in this work. 


\section{References}

1. Albert DM, Jakobiec FA, Miller JW. Albert \& Jakobiec's Principles and Practice of Ophthalmology. Philadelphia, PA, Edinburgh: Saunders/ Elsevier; 2008.

2. Gopinathan U, Garg P, Fernandes M, Sharma S, Athmanathan S, Rao GN. The epidemiological features and laboratory results of fungal keratitis: a 10-year review at a referral eye care center in South India. Cornea. 2002;21(6):555-559.

3. Manzouri B, Vafidis GC, Wyse RK. Pharmacotherapy of fungal eye infections. Expert Opin Pharmacother. 2001;2(11):1849-1857.

4. Desai P, Patlolla RR, Singh M. Interaction of nanoparticles and cell-penetrating peptides with skin for transdermal drug delivery. Mol Membr Biol. 2010;27(7):247-259.

5. Heffernan C, Sumer H, Guillemin GJ, Manuelpillai U, Verma PJ. Design and screening of a glial cell-specific, cell penetrating peptide for therapeutic applications in multiple sclerosis. PLoS One. 2012;7(9): e45501.

6. Mishra B, Wang G. The Importance of Amino Acid Composition in Natural AMPs: An Evolutional, Structural, and Functional Perspective. Front Immunol. 2012;3:221.

7. Semba RD, Enghild JJ, Venkatraman V, Dyrlund TF, van Eyk JE. The Human Eye Proteome Project: perspectives on an emerging proteome. Proteomics. 2013;13(16):2500-2511.

8. Zhang P, Dufresne C, Turner R, et al. The proteome of human retina. Proteomics. 2015;15(4):836-840.

9. Zhang P, Karani R, Turner RL, etal. The proteome of normal human retrobulbar optic nerve and sclera. Proteomics. 2016;16(19):2592-2596.

10. Zhang P, Kirby D, Dufresne C, et al. Defining the proteome of human iris, ciliary body, retinal pigment epithelium, and choroid. Proteomics. 2016;16(7):1146-1153.

11. Dyrlund TF, Poulsen ET, Scavenius C, et al. Human cornea proteome: identification and quantitation of the proteins of the three main layers including epithelium, stroma, and endothelium. J Proteome Res. 2012; 11(8):4231-4239.

12. Galiacy SD, Froment C, Mouton-Barbosa E, et al. Deeper in the human cornea proteome using nanoLC-Orbitrap MS/MS: An improvement for future studies on cornea homeostasis and pathophysiology. J Proteomics. 2011;75(1):81-92.

13. Karring H, Thøgersen IB, Klintworth GK, Møller-Pedersen T, Enghild JJ. A dataset of human cornea proteins identified by Peptide mass fingerprinting and tandem mass spectrometry. Mol Cell Proteomics. 2005;4(9):1406-1408.

14. Nordgaard CL, Berg KM, Kapphahn RJ, et al. Proteomics of the retinal pigment epithelium reveals altered protein expression at progressive stages of age-related macular degeneration. Invest Ophthalmol Vis Sci. 2006;47(3):815-822.
15. Broemstrup T, Reuter N. Molecular dynamics simulations of mixed acidic/ zwitterionic phospholipid bilayers. Biophys J. 2010;99(3):825-833.

16. Gurtovenko AA, Vattulainen I. Effect of $\mathrm{NaCl}$ and $\mathrm{KCl}$ on phosphatidylcholine and phosphatidylethanolamine lipid membranes: insight from atomic-scale simulations for understanding salt-induced effects in the plasma membrane. J Phys Chem B. 2008;112(7):1953-1962.

17. Kucerka N, Liu Y, Chu N, Petrache HI, Tristram-Nagle S, Nagle JF. Structure of fully hydrated fluid phase DMPC and DLPC lipid bilayers using X-ray scattering from oriented multilamellar arrays and from unilamellar vesicles. Biophys J. 2005;88(4):2626-2637.

18. Kučerka N, Nieh M-P, Katsaras J. Fluid phase lipid areas and bilayer thicknesses of commonly used phosphatidylcholines as a function of temperature. Biochim Biophys Acta. 1808;2011(11):2761-2771.

19. Albert R, Veréb Z, Csomós K, et al. Cultivation and characterization of cornea limbal epithelial stem cells on lens capsule in animal materialfree medium. PLoS One. 2012;7(10):e47187.

20. Meletiadis J, Meis JF, Mouton JW, Verweij PE. Analysis of growth characteristics of filamentous fungi in different nutrient media. J Clin Microbiol. 2001;39(2):478-484.

21. Xing Q, Yates K, Vogt C, Qian Z, Frost MC, Zhao F. Increasing mechanical strength of gelatin hydrogels by divalent metal ion removal. Sci Rep. 2014;4:4706.

22. Fang SL, Fan TC, Fu HW, et al. A novel cell-penetrating peptide derived from human eosinophil cationic protein. PLoS One. 2013;8(3): e57318.

23. Wang H, Ma J, Yang Y, Zeng F, Liu C. Highly Efficient Delivery of Functional Cargoes by a Novel Cell-Penetrating Peptide Derived from SP140-Like Protein. Bioconjug Chem. 2016;27(5):1373-1381.

24. Young Kim H, Young Yum S, Jang G, Ahn DR. Discovery of a noncationic cell penetrating peptide derived from membrane-interacting human proteins and its potential as a protein delivery carrier. Sci Rep. 2015;5:11719.

25. Malik E, Dennison SR, Harris F, Phoenix DA. pH Dependent Antimicrobial Peptides and Proteins, Their Mechanisms of Action and Potential as Therapeutic Agents. Pharmaceuticals. 2016;9(4):E67.

26. Sun J, Xia Y, Li D, du Q, Liang D. Relationship between peptide structure and antimicrobial activity as studied by de novo designed peptides. Biochim Biophys Acta. 2014;1838(12):2985-2993.

27. Mohanram H, Bhattacharjya S. Resurrecting inactive antimicrobial peptides from the lipopolysaccharide trap. Antimicrob Agents Chemother. 2014;58(4):1987-1996.

28. Winnicka K, Wroblewska M, Wieczorek P, Sacha PT, Tryniszewska E. Hydrogel of ketoconazole and PAMAM dendrimers: formulation and antifungal activity. Molecules. 2012;17(4):4612-4624. 


\section{Supplementary materials}

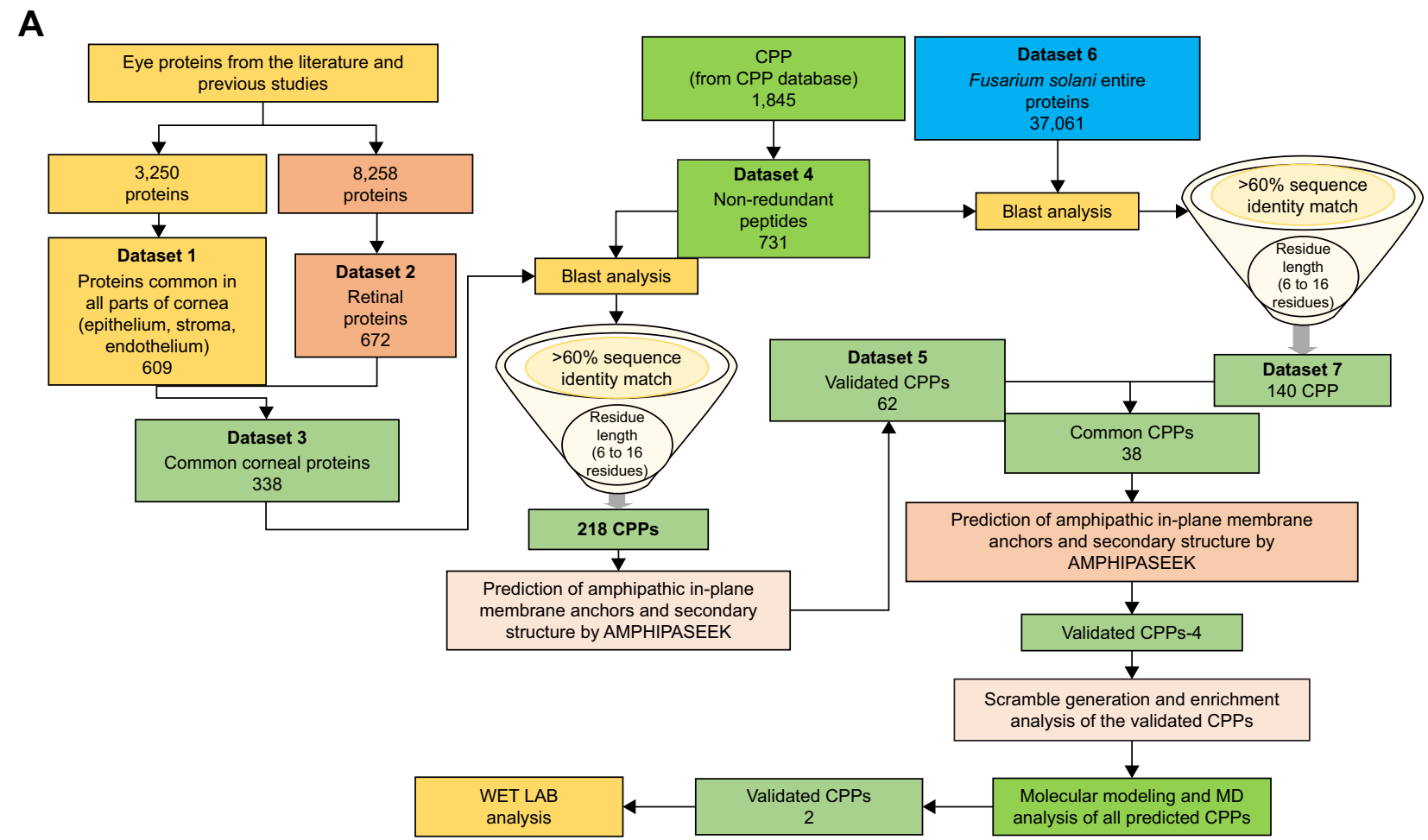

B

\begin{tabular}{|c|c|c|c|c|c|}
\hline Peptide name & Sequence & Length & Net charge & HR $^{\mathbf{a}}$ & GRAVY $^{\mathbf{b}}$ \\
\hline VRF005 & KKKWFETWFTEWPKKKK & 17 & 5 & 29 & -2.024 \\
\hline VRF007 & KDRPIFQLNTSYWEMGA & 17 & 0 & 35 & -0.782 \\
\hline
\end{tabular}

Figure SI (A) Strategy for designing corneal-specific CPPs. (B) Physicochemical properties of the designed peptides.

Notes: aAPD-defined total hydrophobic ratio. 'bRAVY. Greater positive score indicates greater hydrophobicity and vice versa.

Abbreviations: APD, antimicrobial peptide database; CPP, cell-penetrating peptide; GRAVY, grand average of hydropathicity. 
A i

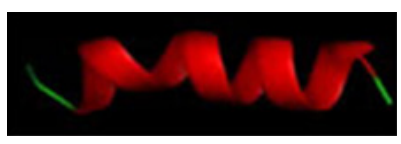

iv

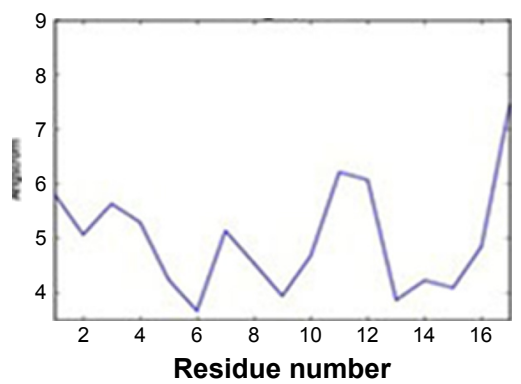

ii

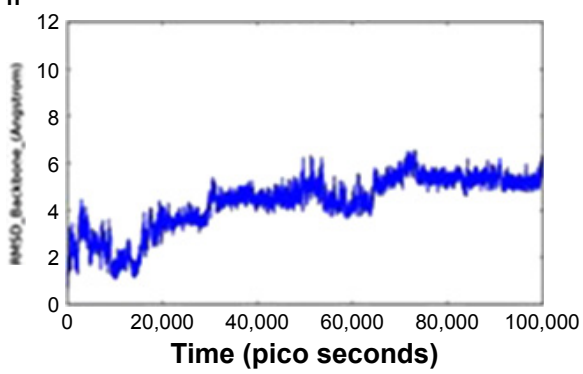

iii

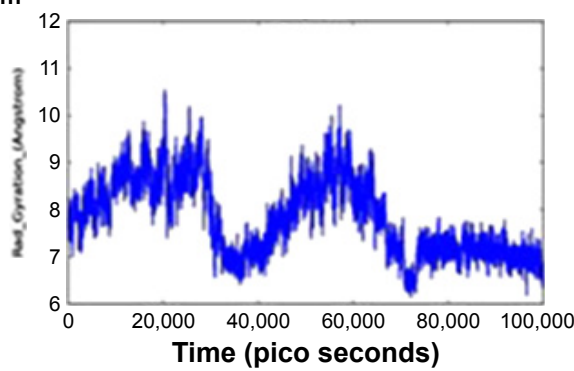

B i

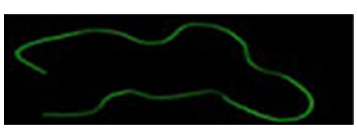

iv

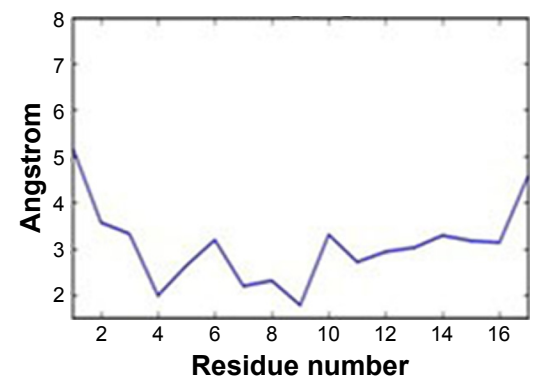

ii
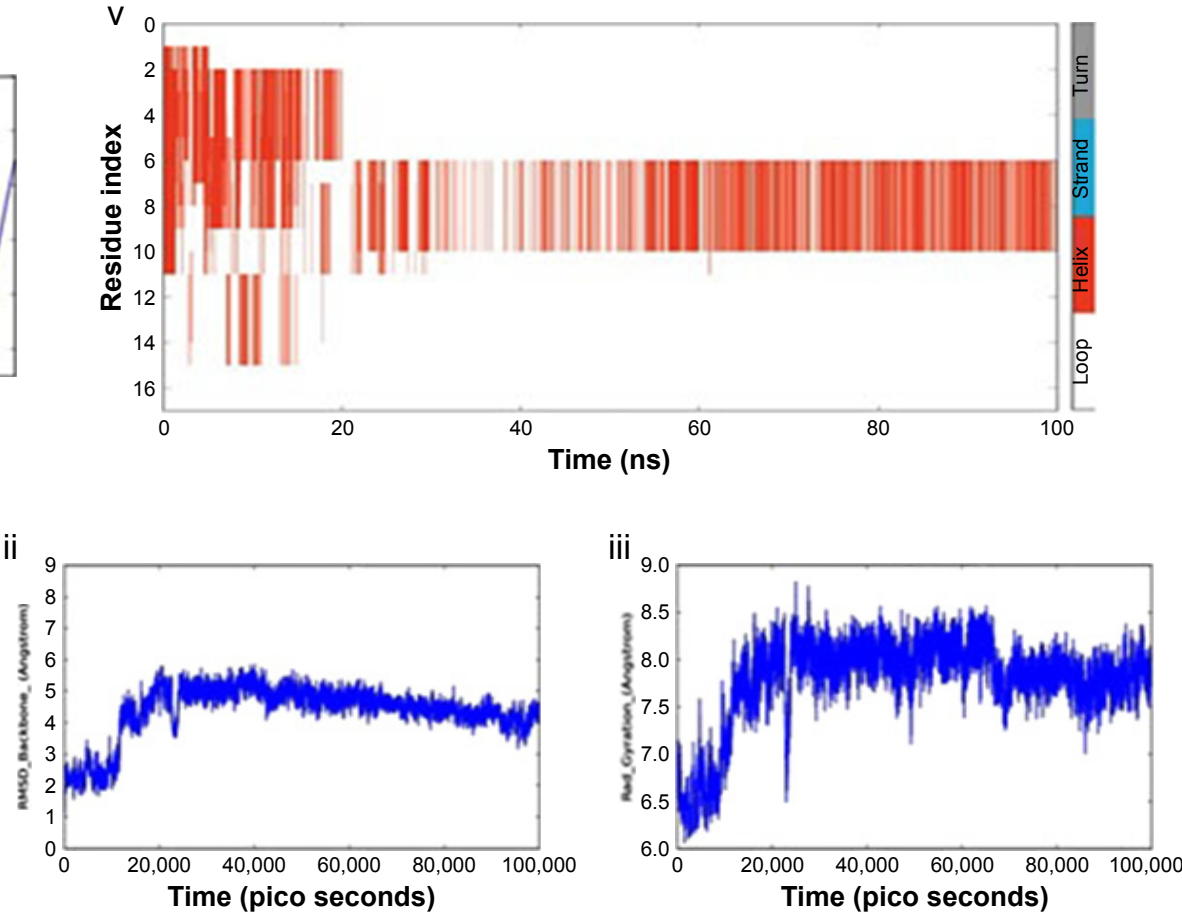

Figure S2 (A) VRF005: (i) structure obtained at the time frame of $100 \mathrm{~ns}$; (ii) RMSD after a time frame of $\sim 70$ ns to $100 \mathrm{~ns}$; (iii) Rg showing maximum compactness after a time frame of $\sim 70 \mathrm{~ns}$; (iv) RMSF fluctuation; and (v) secondary structure element graph. (B) VRF007: (i) structure obtained at the time frame of I00 ns; (ii) RMSD after a time frame of $\sim 70 \mathrm{~ns}$ to $100 \mathrm{~ns}$; (iii) $\mathrm{Rg}$ showing maximum compactness after a time frame of $\sim 70 \mathrm{~ns}$; (iv) RMSF fluctuation; and (v) secondary structure element graph. Abbreviations: RMSD, root-mean-square deviation; RMSF, root-mean-square fluctuations. 


\section{A}

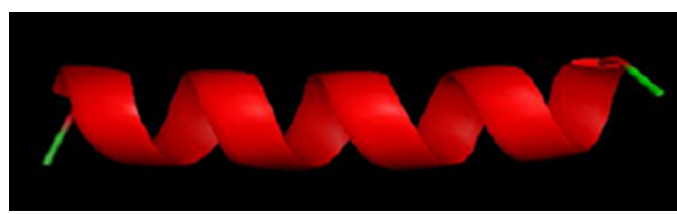

B

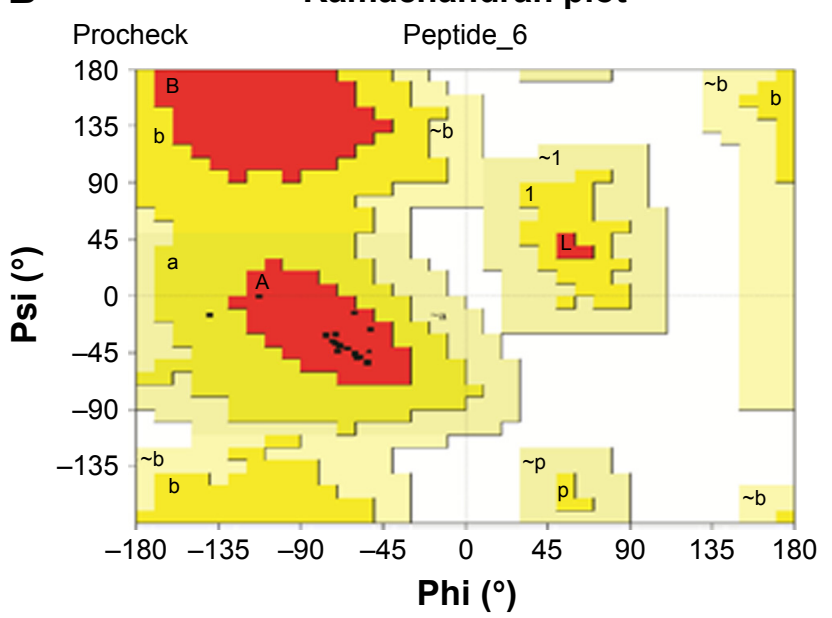

Plot statistics

Residues in most favored regions $(A, B, L)$

Residues in additional allowed regions $(a, b, 1, p)$ Residues in generously allowed regions $(\sim a, \sim b, \sim 1, \sim p)$

Residues in disallowed regions

Number of non-glycine and non-proline residues

\begin{tabular}{cll}
14 & $93.3 \%$ \\
1 & $6.7 \%$ \\
0 & $0.0 \%$ \\
0 & & $0.0 \%$ \\
\cline { 1 - 1 } & & $100.0 \%$ \\
\hline
\end{tabular}

Number of end-residues (excl, Gly, and Pro)

Number of glycine residues (shown as triangles)

Number of proline residues

Total number of residues

2
1

$\frac{0}{18}$

Based on an analysis of 118 structures of residation of at least 2.0 angstroms and R-factor no greater than $20 \%$, a good quality model would be expected to have over $90 \%$ in the most favored regions.

Figure S3 (A) Best model of peptide VRF005. (B) Procheck-generated Ramachandran plot (VRF005 named as Peptide 6).

Abbreviations: excl, excluding; Gly, glycine; Pro, proline.
A

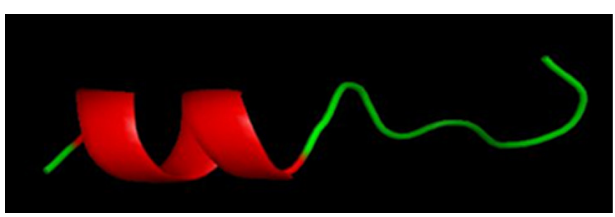

B

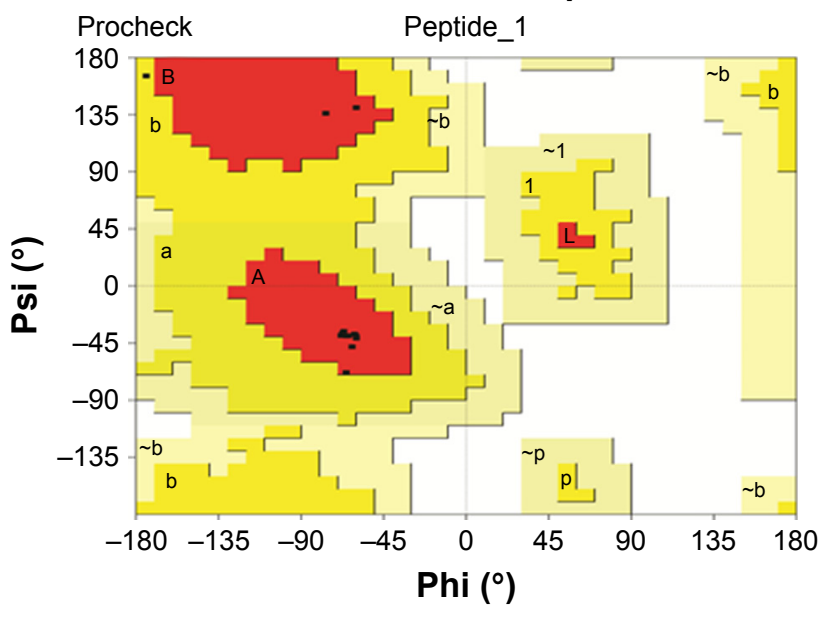

Plot statistics

Residues in most favored regions (A, B, L)

Residues in additional allowed regions $(\mathrm{a}, \mathrm{b}, 1, \mathrm{p})$

$12 \quad 92.3 \%$

Residues in generously allowed regions $(\sim a, \sim b, \sim 1, \sim p)$

Residues in disallowed regions

Number of non-glycine and non-proline residues

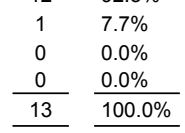

Number of end-residues (excl, Gly, and pro)

Number of glycine residues (shown as triangles)

Number of proline residues

Total number of residues

Based on an analysis of 118 structures of residation of at least 2.0 angstroms and R-factor no greater than $20 \%$, a good quality model would be expected to have over $90 \%$ in the most favored regions.

Figure S4 (A) Best model of peptide VRF007. (B) Procheck-generated Ramachandran plot (VRF007 named as Peptide _ I). 


\section{A}
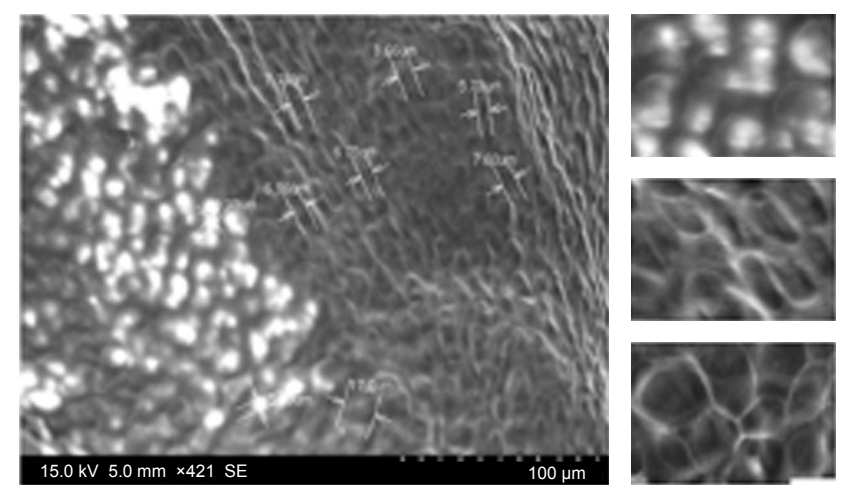

B

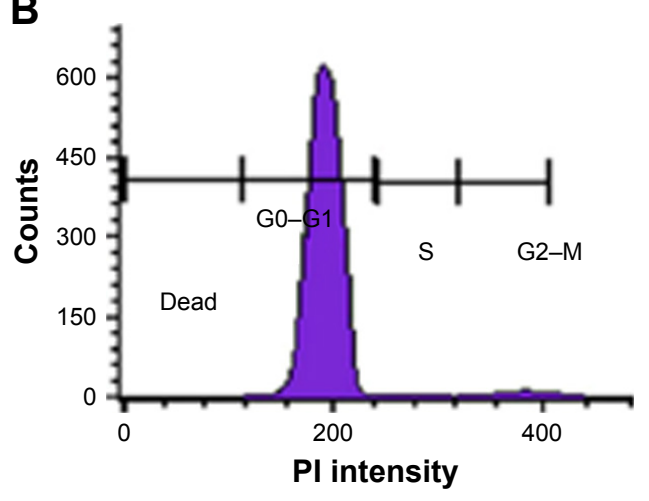

D

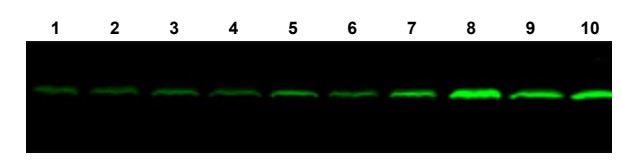

E $\quad$ VRF007+ VRF007+ VRF005+ VRF005+

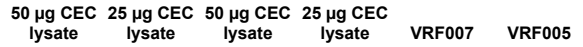
\begin{tabular}{|lllll|}
\hline lysate lysate lysate & lysate & & \\
\hline
\end{tabular}
C

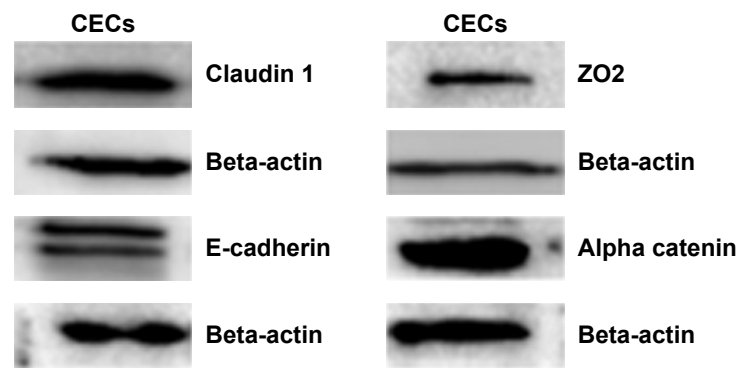

$\mathbf{F}$

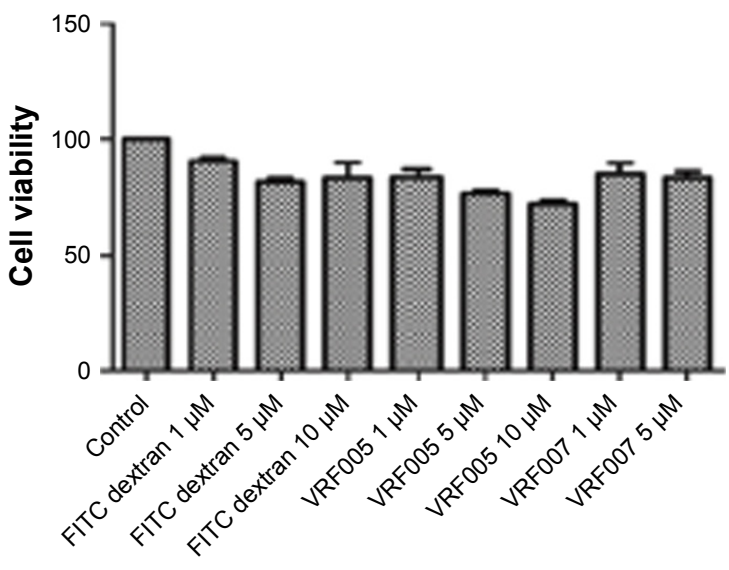

Figure S5 (A) SEM of tissues obtained during surgery. (B) Cell cycle analysis using PI and flow cytometry. (C) Immunoblotting of Claudin I, ZO2, E-cadherin, and alpha catenin of cells isolated from tissues. (D) SDS-PAGE of peptides, VRF005 and VRF007, incubated with human corneal epithelial tissue lysate for 2 hours, lane I, VRF007(I $\mu$ M); lane 2, VRF007(I $\mu \mathrm{M}$ ) with RIPA buffer; lane 3, VRF007 (I $\mu \mathrm{M})$ with $10 \mu \mathrm{g}$ of tissue lysate; lane 4, VRF007(I $\mu \mathrm{M})$ with $20 \mu \mathrm{g}$ of tissue lysate; lane 5, VRF007(I $\mu$ M) with $30 \mu \mathrm{g}$ of tissue lysate; lane 6, VRF005 (I $\mu$ M) with $30 \mu \mathrm{g}$ of tissue lysate; lane 7, VRF005(I $\mu$ M) with $20 \mu g$ of tissue lysate; lane 8, VRF005 (I $\mu$ M) with I0 $\mu g$ of tissue lysate; lane 9, VRF005 (I $\mu \mathrm{M})$ with RIPA buffer; lane 10, VRF007 (I $\mu \mathrm{M})$ alone. (E) SDS-PAGE of peptides, VRF005 and VRF007, incubated with human corneal epithelial tissue lysate for 24 hours. (F) MTT assay for peptides, VRF005 and VRF007, at different concentrations for 24 hours.

Abbreviations: CECs, Corneal Epithelial cells; FITC, fluorescein isothiocyanate; PI, propidium iodide; SEM, scanning electron microscopy. 


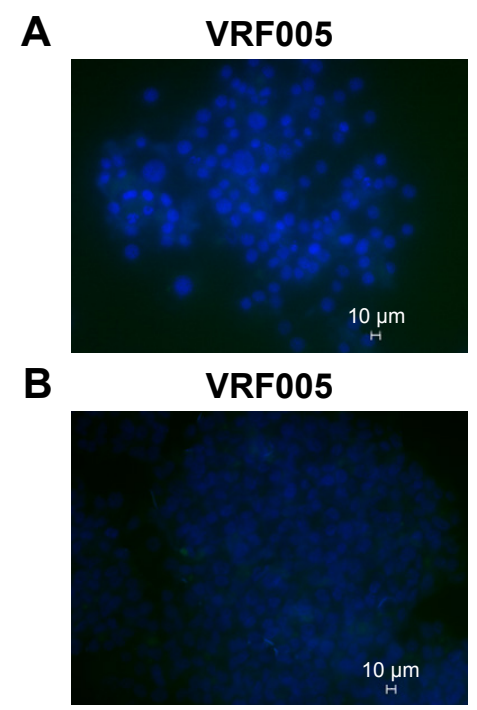

VRF007

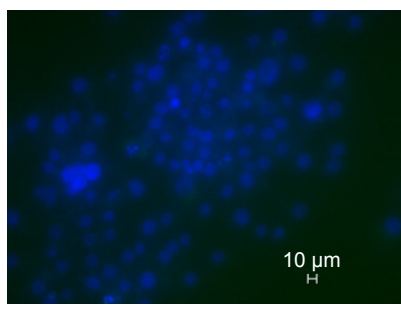

VRF007

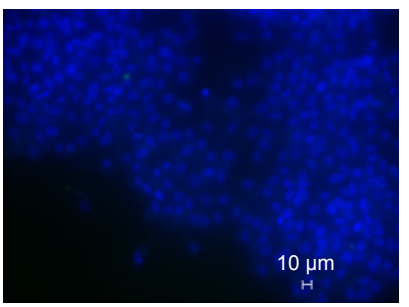

Figure S6 (A) Peptide, VRF005 and VRF007, uptake in MIOM (Muller glial cells) cell line, merged image. (B) Peptide, VRF005 and VRF007, uptake in MCF-7 cell line, merged image.

\section{Publish your work in this journal}

The International Journal of Nanomedicine is an international, peerreviewed journal focusing on the application of nanotechnology in diagnostics, therapeutics, and drug delivery systems throughout the biomedical field. This journal is indexed on PubMed Central, MedLine, CAS, SciSearch $®$, Current Contents ${ }^{\circledR} /$ Clinical Medicine,
Journal Citation Reports/Science Edition, EMBase, Scopus and the Elsevier Bibliographic databases. The manuscript management system is completely online and includes a very quick and fair peer-review system, which is all easy to use. Visit http://www.dovepress.com/ testimonials.php to read real quotes from published authors. 